IZA DP No. 7031

The Efficacy and Efforts of Interest Groups in Post Elections Policy Formation

Gil S. Epstein

Yosef Mealem

Shmuel Nitzan

November 2012 


\title{
The Efficacy and Efforts of Interest Groups in Post Elections Policy Formation
}

\author{
Gil S. Epstein \\ Bar-Ilan University, CReAM and IZA \\ Yosef Mealem \\ Netanya Academic College \\ Shmuel Nitzan \\ Bar-Ilan University
}

Discussion Paper No. 7031

November 2012

\author{
IZA \\ P.O. Box 7240 \\ 53072 Bonn \\ Germany \\ Phone: +49-228-3894-0 \\ Fax: +49-228-3894-180 \\ E-mail: iza@iza.org
}

\begin{abstract}
Any opinions expressed here are those of the author(s) and not those of IZA. Research published in this series may include views on policy, but the institute itself takes no institutional policy positions. The IZA research network is committed to the IZA Guiding Principles of Research Integrity.

The Institute for the Study of Labor (IZA) in Bonn is a local and virtual international research center and a place of communication between science, politics and business. IZA is an independent nonprofit organization supported by Deutsche Post Foundation. The center is associated with the University of Bonn and offers a stimulating research environment through its international network, workshops and conferences, data service, project support, research visits and doctoral program. IZA engages in (i) original and internationally competitive research in all fields of labor economics, (ii) development of policy concepts, and (iii) dissemination of research results and concepts to the interested public.
\end{abstract}

IZA Discussion Papers often represent preliminary work and are circulated to encourage discussion. Citation of such a paper should account for its provisional character. A revised version may be available directly from the author. 


\section{ABSTRACT \\ The Efficacy and Efforts of Interest Groups in Post Elections Policy Formation}

This paper presents a new model of interest groups and policy formation in the legislature. In our setting, the already given party ideological predispositions and power distribution determine the expected policy outcome. Our analysis applies to the case of un-enforced or enforced party discipline as well as to two-party and multi-party (proportional representation) electoral systems. The interest groups' objective is to influence the outcome in their favor by engaging in a contest that determines the final decision in the legislature. Our first result clarifies how the success of an interest group hinges on the dominance of its ideologically closer party and, in general, the coalition/opposition blocks of parties under un-enforced party or coalition/opposition discipline. Such dominance is defined in terms of ideological inclination weighted by power. Our second result clarifies how the success of an interest group hinges on the dominance of its ideology in the ruling coalition (party) in a majoritarian system with enforced coalition (party) discipline. We then clarify under what condition an interest group prefers to direct its lobbying efforts to two parties or the two coalition and opposition blocks of parties under un-enforced discipline rather than to the members of the ruling coalition (party) under enforced discipline. The lobbying efforts under un-enforced and enforced party discipline are also compared. Finally, we clarify the effect of ideological predispositions and power on the efforts of the interest groups.

\section{JEL Classification: D70, D72, D74, D78}

Keywords: policy formation, political parties, ideological predispositions, electoral power, post-elections lobbying, enforced party discipline

\section{Corresponding author:}

Gil S. Epstein

Department of Economics

Bar-Ilan University

Ramat Gan 52900

Israel

E-mail: gil.epstein@biu.ac.il 


\section{Introduction}

In the post-elections political game, the selected policy hinges on the complex interaction between political parties, interest groups and the legislature. The outcome of this game takes into account the political and economic constraints that determine the feasible policy space, the political power and ideology of the parties, the objectives and actions of the interest groups and the mechanism selecting the policy outcome in the legislature. The current study proposes a political economy model of policy formation in the legislature involving interest groups (lobbies) and political parties, whereby the interaction between lobbies is modeled as a contest in which the winner obtains the implementation of his most preferred 'target policy'. Political parties have a given ideological predisposition toward target policies and are not strategic players in the game. Their power within the legislature is also exogenously given. Within this set-up, our first objective is to present a new stylized model that sheds light on the conditions that ensure the effectiveness of an interest group. That is, the conditions for the success of an interest group to influence the policy outcome in its favor by engaging in the lobbying contest that determines the final outcome in the legislature. Our second objective is to study the relationship between the nature of the existing political parties (their power and ideological predisposition) and the intensity of the contest between the interest groups as measured by their exerted efforts. The empirical significance of the proposed model is illustrated by describing a few examples and stylized facts it can explain.

\section{A. An outline of the model and its objectives}

Suppose that the feasible policy set includes the target policies of two interest groups. In the post-elections phase on which we focus, the policy outcome is selected by the legislature (the elected representatives who are members of two or more political parties), taking into account the already given ideological predispositions and power of the existing parties and the lobbying activity of the interest groups. Our majoritarian setting is general because it includes both a two-party system and a multi-party proportional representation electoral system. The legislature consists of two blocks of parties: the ruling coalition that has an absolute majority and the opposition. Note that the ruling coalition and the opposition may consist of a single party. In case of a two-party system, the coalition and the opposition consist of a 
single party. To facilitate the reading, henceforth the term 'party' refers to a single ruling (majority) party or a single opposition (minority) party as well as to blocks of parties, viz., the coalition or opposition that, in general, include more than one party. Likewise, the term 'parties' will refer to the case of two (majority and minority) parties as well as to the coalition and opposition blocks of parties.

The ideological predisposition of the existing parties or their degree of ideological homogeneity is defined in terms of the weights assigned to the target policies of the interest groups. These weights can be interpreted as the proportion of elected party representatives, henceforth 'party representatives', supporting the two target policies of the interest groups. Typically party representatives have similar views regarding primary ideological dimensions. We interpret the policy issue in question as a secondary issue, which is not necessarily related to the ideological dimension that distinguishes between the existing parties (e.g. the attitude regarding the desirable size of the public sector), but to issues such as the desirable degree of regulating $\mathrm{CO}_{2}$ emissions or of regulating the financial system. In other words, we allow two interest groups to lobby the members of two parties, given that there are only two policy options that do not relate to the parties' platform choices. This interpretation justifies our assumption regarding the possible existence of pragmatic parties whose representatives at the legislature support the two secondary policy positions. The second characteristic of the parties is their power - the proportion of seats in the legislature controlled by the party via its elected representatives. Applying the above components of the political environment, it is assumed that without any intervention of the interest groups, given the feasible policy space, the policy outcome in the legislature is determined probabilistically on the basis of the ideological predispositions of the parties and their power. The randomness in the legislature's decision making reflects the effect of the probabilistic nature of the party representatives' voting both under the assumption that party discipline is not enforced or enforced. Members of the legislature may not participate in the vote because of absence or vote in a volatile manner in contrast to their declared ideological disposition. The assumed particular dependence of the policy outcome on the party characteristics reflects the democratic nature of the legislature; the application of (simple) majority rule under un-enforced party discipline. Alternatively, in a multiparty proportional representation electoral system with enforced party discipline, the 
outcome in the legislature hinges just on the random voting of the representatives who are members of the ruling coalition that has an absolute majority.

The activity of the interest groups is induced by their ability and desire to affect the final policy outcome in the legislature. In our model of policy formation, the interest groups put efforts and engage in a lobbying contest that affects the choice probability of their target policy. To examine the effect of the interest groups on the final policy outcome in the legislature, we assume that the policy outcome in the legislature depends on the resources directed by the interest groups to the party representatives and that the effectiveness of these resources hinges on the support of the party representatives in the target policies of the interest groups weighted by the power of the parties. Under this type of contests, we clarify the relationship between the already determined exogenous party characteristics and the intensity of the contest (the resources expended by the players in the contest game, viz., by the competing interest groups).

Since it is naturally recognized that institutions and interest groups, in particular, matter, we will examine the effectiveness of interest groups by examining whether their simultaneous involvement in a contest changes the selected policy in their favor. Without their contest activity, the random policy outcome hinges just on the power and ideological predisposition of the existing parties. When the interest groups take part in the contest, the policy outcome also depends on their efforts, namely, the resources they direct to the party members. Our first objective is to establish the necessary and sufficient conditions for the efficacy of an interest group. These conditions can be used to determine the relationship between the initial and final (before and after the contest takes place) advantage of a target policy of an interest group. In particular, we clarify whether an initial advantage of a policy (a prior probability of selection higher than 0.5 ) is necessarily preserved, or whether such an initial advantage can be overturned. These conditions are determined, first, assuming un-enforced party discipline. In this case, the interest groups direct their lobbying efforts to members of all the parties because their potential supporters are usually members of both the coalition and opposition parties. And, since party discipline is not enforced, the potential support is effective when the legislature makes its decision regarding the final policy outcome. We then study the condition for the efficacy of an interest group, assuming enforced party discipline. In this case, lobbying efforts are directed just to the members of the ruling coalition (party) before 
the party line is decided. ${ }^{1}$ Given the conditions for the efficacy of an interest group under un-enforced and enforced party discipline, we can compare the desirability of enforced and unenforced party discipline from the viewpoint of the interest groups as well as from the social point of view. In the former case, the probability of becoming effective is used as the criterion applied by an interest group. In the latter case, we apply the aggregate efforts incurred by the interest groups as the social welfare criterion. The second objective of the paper is to examine the relationship between the already shaped party characteristics (their power and ideological heterogeneity) and the intensity of the contest between the interest groups as measured by their aggregate efforts. In particular, we focus on parties with extreme characteristics that are often obtained as equilibrium outcomes in models of electoral equilibrium, i.e. symmetric parties with converging ideological predispositions and polarized parties with extreme different ideological predispositions. More generally, for any pattern of party characteristics, we examine the effect of changes in the parameters of our model (the degree of ideological heterogeneity of a party, the power distribution of the parties and the stakes of the interest groups) on the contestants' efforts (intensity of the contest). We also compare the lobbying efforts of the interest groups under unenforced and enforced party discipline

\section{B. Relationship to the literature}

Political parties and special interest groups are basic characteristics of democracies. The party ideologies, internal composition and political power influence the policy chosen by the legislature. Such policy is also affected by the activities of interest groups, typically various forms of direct lobbying, informational lobbying and campaign contributions. The influence activities of interest groups are directed both to politicians competing for power before the elections who are the prospective rulers or to elected politicians and already functioning government officials.

The literature on party modeling focuses on endogenous party formation. Likewise, in the electoral-competition literature, the emphasis is on the determination of the party platforms or pre-elections preferred policies and on the secured support of

\footnotetext{
${ }^{1}$ Notice that under enforced party discipline, we can focus on the members of the ruling coalition because the final outcome in the legislature does not depend on whether party discipline is enforced or not enforced on the members of the (minority) opposition. In contrast, under un-enforced party discipline, the final outcome in the legislature is affected by the voting of the members of all the parties (coalition and opposition parties).
} 
voters in the competing parties. In our model the parties are already shaped and we take their ideological inclination or degree of heterogeneity as well as their political power as given.

In the special interest-group literature, attention is directed to the formation of the groups, to the relationship between interest groups and political parties or to the relationship between interest groups and the ruling politicians or bureaucrats, van Winden (1999), Wittman (2009). In one still growing part of this literature, the methodology of political contests is used to study the effect of lobbying and influence activities by interest groups on the decisions of the ruling politicians or government officials, Konrad (2009). For various attempts to examine public policy determination in contests see Epstein and Nitzan (2007). In our model, the contest methodology is applied to examine whether the resources expended by the already formed interest groups (resources that are directed to the elected party representatives) are effective, namely, whether they are able to change the policy outcome in their favor. Notice that the parties are assumed to be effective via their representatives in determining the decision of the legislature regarding the final policy outcome. Our study combines the effect of the interest groups to that of the parties in order to examine the policy outcome of the legislature. In contrast to the approach of Grossman and Helpman (2001), as well as Epstein and Nitzan (2007), we focus on the strategic interaction between the interest groups, disregarding the strategic interaction between interest groups and policy makers and the strategic interaction between the parties or between their representatives. The effect of the interest groups on the final policy outcome is determined through their effect on the party representatives, given the assumed relationship between the ideological predispositions and power of the parties, the efforts of the interest groups and the decision of the legislature.

The literature on campaign contributions proposes two motives of interest groups: an electoral motive and influence motive. The former motive does not apply in our setting because the platforms and the power of the parties are already determined. The latter motive applies in our setting, not because interest groups influence politicians' positions, but because they influence the abilities of the party representatives to affect the final policy outcome in the legislature. Given our focus on the post elections phase, our modeling is distinctive in its enabling the clarification of the role of party characteristics (power and heterogeneity) on the intensity of the 
contest between the interest groups (the aggregate resources directed to the parties by the contestants). ${ }^{2}$

Finally, our interest groups do not offer contingent contributions as in Becker (1983) or Grossman and Helpman (2001). Their efforts are unconditional because they directly affect their effectiveness in the legislature. While our model has antecedents in the probabilistic voting literature, rather than viewing the decisions of the voters or their preferences as probabilistic, Austen-Smith (1987), Baron (1994), Enelow and Hinich (1982), Coughlin and Nitzan (1981), Intriligator (1973), we assume that the decisions of the legislature are probabilistic.

\section{Empirical relevance}

The proposed model of interest groups' influence on post-elections politics relates to interesting phenomenon in many political-economic environments and it should be tested empirically. But concepts such as ideological inclination of parties and stakes of interest groups are rather complex concepts and their measurement may pose a severe challenge.

Nevertheless, to illustrate the empirical relevance of the model let us focus on the problem of "extremism"; religious, economic, political or cultural extremism of political parties or of interest groups. Since the end of the Second World War, increased or reduced ideological polarization between political parties and interest groups can be observed in many societies. For example, ideological polarization has apparently been reduced regarding issues such as environmental policy, reducing the proliferation of nuclear weapons or the need of government intervention in the regulation of the economy and, in particular, the financial sector. However, ideological polarization has increased regarding various religious issues, the desirable immigration or anti-terror policy and, certainly, regarding economic policy related to income or wealth redistribution. In these contexts two interesting questions arise. First, what makes an interest group successful in enhancing its target policy? Second, what makes interest groups more active (exert more efforts on lobbying)? The results obtained in our tractable model shed light on these issues and the relevance of our

\footnotetext{
${ }^{2}$ Bennedsen and Feldmann (2002) have studied the impact of the different European and American majoritarian legislative structures on the intensity of lobbying, applying a model of informational lobbying. For a review of the literature on informational lobbying, see Grossman and Helpmann (2001).
} 
findings is illustrated in the discussion following each of the main theorems. Empirical testing of these results is a worthwhile challenging task.

\section{Party characteristics and the selected policy}

Suppose that the feasible policy set in the economic-political environment includes the policies $x$ and $y$, that represent the desirable targets of two interest groups; typically passing or rejecting a proposed law. This is the reason why the interest groups are indexed by $x$ and $y$. The final policy outcome is one of these two policies and it is selected by the legislature as long as the government is functioning. In the post-elections phase on which we focus, the legislature chooses the final policy outcome taking into account the already given electoral power and ideological predispositions of the existing parties and the lobbying activity of the interest groups. The strategy chosen by an interest group is any non-negative lobbying effort. The parties are not strategic players in the influence game that we study.

The first characteristic of party $i$ is its power $d_{i}$. This power index represents its relative strength in the legislature. In a two party system, $d_{1}+d_{2}=1$. Recall that in the context of a multi-party proportional representation electoral system, $d_{1}$ and $d_{2}$ are interpreted as the relative strength of the ruling coalition and opposition parties.

The second characteristic of party $i$ is its ideological predisposition which is defined in terms of the target policies $x$ and $y$ of the interest groups. Specifically, party $i$ 's ideological predisposition is defined in terms of the weights $\delta_{i x}$ and $\delta_{i y}=1-\delta_{i x}$, $0 \leq \delta_{i x} \leq 1$, that it assigns, respectively, to policy $x$ and policy $y$. The weights can be interpreted as the proportion of party representatives in the legislature supporting the two policies or the likelihood that the party representatives support the target policies of the interest groups. These weights can therefore be used to identify the ideological disposition of party $i$ : when $\delta_{i x}$ is close to 1 or close to 0 , the party is homogeneous or cohesive; it supports or most of its members support one of the policies $x$ or $y$. When $\delta_{i x}$ is close to 0.5 , the party is heterogeneous or factionalist; it almost equally supports or its members almost equally support the different policies $x$ and $y$. Henceforth the degree of heterogeneity of party $i$ is measured by $\sqrt{\delta_{i x} \delta_{i y}}$. This measure ranges between 0 and 0.5 . When party $i$ is completely homogeneous, $\delta_{i x}$ or $\delta_{i y}$ is equal to 1 
and $\sqrt{\delta_{i x} \delta_{i y}}=0$. When the party is heterogeneous $\delta_{i x}$ and $\delta_{i y}$ are equal to 0.5 and $\sqrt{\delta_{i x} \delta_{i y}}=0.5 .^{3}$

In a democracy, decisions in the legislature are made applying a majority rule. If all members of the legislature take part in a decision, party discipline is not enforced and the value of $d_{1} \delta_{1 x}+d_{2} \delta_{2 x}$ is larger than 0.5 , then policy $x$ would become the decision of the legislature in probability 1 . In practice, and in particular when a decision is made on a secondary issue, not all the members of the legislature take part in the decision and vote in accordance with their declared ideological disposition. Typically, it is likely that some of the elected representatives who are known supporters of policy $x$ do not take part in the vote or do vote, but in a volatile manner in contrast to their declared ideological disposition. So there is a chance that $y$ is the accepted policy, despite the fact that $d_{1} \delta_{1 x}+d_{2} \delta_{2 x}$ is larger than 0.5. Hence, applying the above elements of the political environment, it is assumed that without any intervention of the interest groups, the policy outcome in the legislature is determined probabilistically reflecting the parties' ex-ante power $d_{i}$ and their predisposition for $x$ and $y, \delta_{i x}$ and $\delta_{i y}$. Specifically, the probability that policy $x$ is selected by the legislature is equal to $p_{x}^{0}=d_{1} \delta_{1 x}+d_{2} \delta_{2 x}$, and, similarly, the probability that $y$ is the final policy outcome is equal to $p_{y}^{0}=d_{1} \delta_{1 y}+d_{2} \delta_{2 y}$. By definition, these two probabilities sum up to 1 .

Under un-enforced party discipline, the final decision in the legislature depends on the votes of the members of all the parties (coalition members as well as those of the opposition members). In this case, the interest groups can affect the voting of the members in the coalition and opposition and our model applies. Under enforced party discipline, the policy of the ruling party (coalition) is based on the voting of its members. Once a decision is reached, discipline in the ruling party (coalition) is enforced and the preferred decision becomes that of the legislature. In this case, the interest groups can affect the voting of the members of the ruling party (coalition) and our model applies. The activity of the interest groups is induced by

\footnotetext{
${ }^{3}$ Note that viewing the degree of heterogeneity or ideological predisposition of party $i$ as a random variable with a Bernoulli distribution with a probability of $\delta_{i x}$ that a party member supports policy $x$, the standard deviation of the party's ideological disposition is $\sqrt{\delta_{i x} \delta_{i y}}$.
} 
their ability and desire to affect the final policy outcome in the legislature. In particular, the interest groups can put efforts and engage in a lobbying contest that affects the choice probability of their preferred policy. Let $p_{x}$ denote the choice probability of policy $x$. Our assumption on $p_{x}$ disregards explicit and detailed consideration of the form of lobbying practiced by the interest groups, the identity of the party representatives in the legislature to whom resources are directed, as in Baron (2006). Nevertheless, under un-enforced party discipline, it does take into account the investment portfolio of the interest groups in the representatives of the two parties, the power of the parties and the ideological dispositions of the parties that jointly determine in a subtle and democratic way the final policy outcome. Under enforced party discipline, we take into account the investment portfolio of the interest groups in the representatives of the ruling party and the ideological dispositions of these members who determine by majority rule the decision of the ruling party and, in turn, the decision in the legislature. The way lobbying determines the final policy outcome is assumed to be captured by a modification of the widely studied logit contest success function adapted to our setting. It should be viewed as a shortcut for describing the complex democratic institutional environment that allows random behavior of the party representatives. As described above, when the interest groups do not intervene, the assumed contest success function does take into account the "majority rule" because, under un-enforced party discipline, the decision of the legislature hinges on the power of the parties and the number of elected representatives that support the two policies. Under enforced party discipline, the assumed contest success function takes into account the "majority rule" applied within the ruling party to determine its supported policy which becomes that of the legislature. With lobbying, the contest success function also takes into account the efforts directed by the interest groups to the party representatives. Again, under certainty, the critical support for a policy in a legislature that makes decisions by simple majority is $50 \%$ of the votes. Under random voting, each policy is chosen in some probability. The critical choice probability for a policy, say $x$, is 0.5 . In an analogous manner to simple majority under certainty, the probability that $x$ is chosen is assumed to be the relative total support for $x$ among the representatives of all the parties (the ruling parties) when party discipline is not enforced (is enforced). This probability is now affected by the efforts of the interest groups. 
The interest groups direct resources $x_{i}$ and $y_{i},(i=1,2)$ to the elected representatives of the two parties under un-enforced party discipline or to the elected representatives of the ruling party (coalition) under enforced party discipline. The more resources they direct to representatives of party $i$ the higher the likelihood that these representatives will vote in favor of their target policy. Recall, that even without the efforts exerted by the interest groups, usually each party has representatives who support the different policies. The total initial support of a policy is represented by the sum of the ideological predispositions for that policy in the two parties weighted by the power of the parties. The efforts of the interest groups affect precisely this initial support in each party of the two policies $x$ and $y$ yielding the aggregate choice probabilities of the two policies in the legislature. Notice that this aggregation function allows a decentralized legislature with low voting cohesion or a parliamentary legislature with strong voting cohesion. ${ }^{4}$ Suppose then that when the investment of interest groups $x$ or $y$ in at least one of the parties is positive, the probability that the legislature approves the policy $x$ is given by:

$$
p_{x}=\frac{\sum_{i=1}^{2} d_{i} \delta_{i x} x_{i}^{\alpha}}{\sum_{i=1}^{2} d_{i} \delta_{i x} x_{i}^{\alpha}+\sum_{i=1}^{2} d_{i} \delta_{i y} y_{i}^{\alpha}}
$$

Otherwise $p_{x}=p_{x}^{05} .^{5}$ Notice that the function is well defined since when the denominator is zero, $p_{x}=p_{x}^{0}$. Furthermore, the definition of this function is analogous to the definition of Tullock's (1980) lottery contest success function. In the latter case, when no effort is exerted by the contestants, their winning probabilities are equal to 0.5 ( $p_{x}^{0}$ in our case). We also assume that the marginal effectiveness of effort exerted by an interest group is decreasing, that is, $0<\alpha<1$. Note that when $\alpha \rightarrow 0$, by equation (1), $p_{x}=d_{1} \delta_{1 x}+d_{2} \delta_{2 x}=p_{x}^{0}$. This means that both parties are not affected by the lobbying efforts of the interest groups. The reason is that in such a case being affected by lobbying implies incurring a very high cost due to apparent decline in the

\footnotetext{
${ }^{4}$ A possible formal normative justification of this particular form can be based on the axiomatic approach of Clark and Riis (1998).

5 The assumed biased contest success function has a nice foundation as a technology of persuasion based on Bayesian updating, see Skaperdas and Vaidya (2009).
} 
party reputation. An increase in $\alpha$ means a reduced decline in the party reputation and, therefore, a higher responsiveness to lobbying.

The effect of the investment of interest group $x$ in the representatives of party $i$ hinges on the parameter $\alpha$ and on $d_{i} \delta_{i x}$ - the electoral power of party $i$ weighted by its tendency to support the policy $x$ (which is indicative of its degree of heterogeneity). The effect of the investment portfolio of interest group $x$ in both parties is the sum $\sum_{i=1}^{2} d_{i} \delta_{i x} x_{i}^{\alpha}$. A similar interpretation applies to $\sum_{i=1}^{2} d_{i} \delta_{i y} y_{i}^{\alpha}$ - the effect of the investment of interest group $y$ in the representatives of the two parties. The total effect of the efforts directed by the two interest groups to all the elected representatives is therefore represented by $\sum_{i=1}^{2} d_{i} \delta_{i x} x_{i}{ }^{\alpha}+\sum_{i=1}^{2} d_{i} \delta_{i y} y_{i}{ }^{\alpha}$. Hence, $p_{x}$ specifies the effect of the efforts directed by group $x$ to the representatives of the two parties who support $x$ relative to the total effect of the efforts directed by the two interest groups $x$ and $y$ to all the members in the legislature. Recall that the probability that the legislature approves policy $y$ is given by $1-p_{x}$ and note that, in equilibrium of the lobbying contest, it is impossible that an interest group exerts no effort, although it may direct efforts just to the representatives of one party (see footnote 5).

Let $n_{x}$ and $n_{y}$ denote, respectively, the benefit of interest groups $x$ and $y$ from their target policies. The expected net payoff of the risk neutral interest group $x$ from taking part in the legislative contest is:

$$
u_{x}=p_{x} n_{x}-\sum_{i=1}^{2} x_{i}
$$

and, similarly, the expected net payoff of the risk neutral interest group $y$ is:

$$
u_{y}=\left(1-p_{x}\right) n_{y}-\sum_{i=1}^{2} y_{i}=p_{y} n_{y}-\sum_{i=1}^{2} y_{i}
$$

To examine the conditions that give rise to effective interest group participation in the legislative contest and to expose the relationship between party 
characteristics and the activism of the interest groups (the resources they direct to the parties), we turn to the equilibrium analysis of the contest.

\section{The contest equilibrium}

The necessary conditions for Nash equilibrium of the contest between the two interest groups yield the equilibrium efforts of the interest groups directed to the elected representatives of party $j:^{6}$

$$
x_{j}=\frac{\alpha n_{x} k^{\alpha}\left(d_{j} \delta_{j x}\right)^{\frac{1}{1-\alpha}}\left(\frac{A}{B}\right)^{1-\alpha}}{\left[k^{\alpha}\left(\frac{A}{B}\right)^{1-\alpha}+1\right]^{2} A}
$$

and

$$
y_{j}=\frac{\alpha n_{y} k^{\alpha}\left(d_{j} \delta_{j y}\right)^{\frac{1}{1-\alpha}}\left(\frac{A}{B}\right)^{1-\alpha}}{\left[k^{\alpha}\left(\frac{A}{B}\right)^{1-\alpha}+1\right]^{2} B}
$$

where $A=\sum_{i=1}^{2}\left(d_{i} \delta_{i x}\right)^{\frac{1}{1-\alpha}}, B=\sum_{i=1}^{2}\left(d_{i} \delta_{i y}\right)^{\frac{1}{1-\alpha}}$ and $k=\frac{n_{x}}{n_{y}}$. With no loss of generality, we henceforth assume that $k \geq 1 .^{7}$ Notice that $A$ and $B$ can be interpreted as measures of support of both parties, respectively, in interest groups $x$ and interest group $y$. The total equilibrium lobbying efforts of the interest groups that are directed to the parties are equal to:

\footnotetext{
${ }^{6}$ The assumption that $\alpha<1$ with a continuous action space on $[0, \infty]$ guarantees an interior equilibrium. Notice that for the contest to be meaningful, the ideological predisposition of the two parties towards each of the interest groups cannot be zero, because otherwise an interest group will not have any impact on the choice probability of its target policy that will be always equal to zero. The necessary equilibrium conditions are: $\frac{\partial u_{x}}{\partial x_{j}}=\frac{\partial u_{y}}{\partial y_{j}}=0, j=1,2$, see (2) and (3). Note that, in equilibrium under the assumption that $\alpha<1$, it is impossible that an interest group makes no effort (does not invest in any party), because in such a case its rival can ensure that its target policy is adopted by the legislature with probability 1 by exerting a negligible positive effort and directing it to either party. However, we do not rule out the possibility that, in equilibrium, an interest group exerts efforts, but direct them just to the elected representatives of one party, but does not invest at all in the other party. By (4), this will happen when the ideological predisposition of the latter party toward the target policy of the interest group is equal to zero.

${ }^{7}$ The benefit of an interest group from winning the contest represents the difference in its valuation between its preferred target policy and the alternative policy. Such difference can be interpreted as difference in marginal cost which means that $k>1$ may also represent an interest group with ample resources, say the nuclear power lobby, competing with a lobby with modest financial capabilities, say the green movement.
} 


$$
\sum_{i=1}^{2} x_{i}=\frac{\alpha n_{x} k^{\alpha}\left(\frac{A}{B}\right)^{1-\alpha}}{\left[k^{\alpha}\left(\frac{A}{B}\right)^{1-\alpha}+1\right]^{2}} \quad \text { and } \quad \sum_{i=1}^{2} y_{i}=\frac{\alpha n_{y} k^{\alpha}\left(\frac{A}{B}\right)^{1-\alpha}}{\left[k^{\alpha}\left(\frac{A}{B}\right)^{1-\alpha}+1\right]^{2}}
$$

The total equilibrium efforts exerted in the contest, efforts that can be interpreted as a measure of the contest intensity, are therefore equal to:

$$
\sum_{i=1}^{2} x_{i}+\sum_{i=1}^{2} y_{i}=\frac{\alpha k^{\alpha}\left(n_{x}+n_{y}\right)\left(\frac{A}{B}\right)^{1-\alpha}}{\left[k^{\alpha}\left(\frac{A}{B}\right)^{1-\alpha}+1\right]^{2}}
$$

By (1) and (4), the winning probability of interest group $x$ in the unique interior contest equilibrium (see footnote 6) is equal to:

$$
p_{x}=\frac{k^{\alpha}\left(\frac{A}{B}\right)^{1-\alpha}}{k^{\alpha}\left(\frac{A}{B}\right)^{1-\alpha}+1}
$$

\section{The conditions for interest-group efficacy}

Our first concern is to examine the conditions under which the involvement of the interest groups in the contest makes one of them effective. An interest group is called effective if the winning probability of its target policy increases due to its taking part in the contest. In particular, interest group $x$ is effective if $p_{x}>p_{x}^{0}=d_{1} \delta_{1 x}+d_{2} \delta_{2 x}$. Recall that under un-enforced party discipline, $d_{1}$ and $d_{2}$ are the relative strength of the two parties (blocks of parties). In a system with enforced party discipline, a ruling party (coalition) $j$, determines the final policy outcome. In this case $d_{j}=1$, and the lobbying efforts of the interest groups are directed just to the members of party $j$.

Note that even when interest group $\mathrm{x}$ is ineffective, that is, $p_{x}<p_{x}^{0}=d_{1} \delta_{1 x}+d_{2} \delta_{2 x}$, in equilibrium, it will take part in the contest and exert positive efforts. The reason is that otherwise its winning probability drops to zero, 
even when its rival exerts negligible efforts. To avoid this possibility and ensure that its winning probability is positive, interest group $x$ exerts some efforts despite its ineffectiveness.

The efficacy conditions are important because they can explain the cause of success in the post-elections competition and, in particular, empirical data regarding interest groups' performance as estimated on the basis of time-series or cross-section data. According to the efficacy definition, one may wonder whether an interest group that is the underdog in the absence of a contest, i.e., $p_{x}^{0}<0.5$ necessarily remains the underdog, even if it is effective. ${ }^{8}$ In other words, the question is whether the effectiveness of an interest group can improve its status, but cannot reverse it (that is, cannot change it from an underdog (before the contest is held) to a favorite (after the contest takes place)). Formally, assuming, with no loss of generality, that $p_{x}^{0}<0.5$, can interest group $x$ take part in the contest and be effective such that it is no longer the underdog, $p_{x}>0.5>p_{x}^{0}$ ? Let us first present the conditions under which a party is effective. These conditions depend on whether the interest group valuations of their target policies are different or identical and on whether party discipline is enforced. The first result holds assuming un-enforced party discipline.

Theorem 1: Suppose that party discipline is not enforced. In the symmetric situation where the prize valuations of the interest groups are identical, $k=1$, an interest group (say $x$ ) is effective if and only if (i) there exists a party $i$ that is more inclined to the target policy $x$ than the other party $j\left(\delta_{i x}>\delta_{j x}\right)$ and (ii) the degree of heterogeneity of party $i$ weighted by its power is larger than that of the other party $j$ $\left(d_{i} \sqrt{\delta_{i x} \delta_{i y}}>d_{j} \sqrt{\delta_{j x} \delta_{j y}}\right.$ ). If $k>1$, the above conditions are sufficient for the efficacy of group $x .^{9}$

The proofs of this theorem and all other results are relegated to the Appendix.

For symmetric contestants, $k=1$, the two conditions in Theorem 1 are necessary and sufficient for the efficacy of interest group $x$. Similar conditions are necessary and

\footnotetext{
${ }^{8}$ The terms underdog and favorite are due to Dixit (1987).

${ }^{9}$ Recall that, in a multi-party context, the term 'party' relates to one of the two blocks of parties: the ruling (majority) coalition and the (minority) opposition.
} 
sufficient for the efficacy of interest group $y$. For asymmetric contestants, $k>1$, however, these conditions are only sufficient for the efficacy of the contestant with the higher valuation of his target policy, interest group $x$.

Note that $\delta_{i x}>\delta_{j x}$ implies that $\delta_{i y}<\delta_{j y}$. That is, condition (i) ensures ideological proximity of $i$ to interest group $x$ and this means that $j$ is closer ideologically to interest group $y$. Condition (ii) ensures that $d_{i} \sqrt{\delta_{i x} \delta_{i y}}>d_{j} \sqrt{\delta_{j x} \delta_{j y}}$. That is, $i$ 's degree of heterogeneity weighted by its power is larger than that of $j$.

If the above two conditions are satisfied, then by Theorem 1 ,

(1) If party $i$ is less heterogeneous than party $j, \sqrt{\delta_{i x} \delta_{i y}}<\sqrt{\delta_{j x} \delta_{j y}}$, then condition (ii), $d_{i} \sqrt{\delta_{i x} \delta_{i y}}>d_{j} \sqrt{\delta_{j x} \delta_{j y}}$, requires that the power of $i$ is larger than the power of $j$, $d_{i}>d_{j}$. Furthermore, since $i$ is less heterogeneous, then when combining condition (i), one of the following inequalities must be satisfied. Either $\delta_{i x}>\delta_{j y}>\delta_{j x}>\delta_{i y}$ or $\delta_{i x}>\delta_{j x}>\delta_{j y}>\delta_{i y}$, which means that $\delta_{i x}>0.5$. We therefore obtain the following conclusion: If interest group $x$ is effective and the stronger less heterogeneous party $i$ is ideologically closer to its target policy than the other party $j$, then party $i$ is closer to $x$ not only relative to the other party $\left(\delta_{i x}>\delta_{j x}\right.$ ), but also relative to its inclination to the target policy $y$ of the other interest group $\left(\delta_{i x}>0.5\right)$.

(2) If $i$ is more heterogeneous than $j, \sqrt{\delta_{i x} \delta_{i y}}>\sqrt{\delta_{j x} \delta_{j y}}$, then condition (ii), $d_{i} \sqrt{\delta_{i x} \delta_{i y}}>d_{j} \sqrt{\delta_{j x} \delta_{j y}}$, does not require that $d_{i}>d_{j}$. That is, the more heterogeneous party $i$ can be the weaker party, $d_{i}<d_{j}$.

Suppose now that in the absence of a contest interest group $x$ is the underdog. By Theorem 1, if conditions (i) and (ii) are satisfied, it can take part in a contest against interest group $y$, and be effective. The following example shows that the involvement in the contest can be advantageous to such an extent that interest group $x$ becomes the favorite.

Example 1: Suppose that $\delta_{1 x}=\frac{4}{7}, \delta_{1 y}=\frac{3}{7}, \delta_{2 x}=\frac{1}{6}, \delta_{2 y}=\frac{5}{6}, d_{1}=0.7, d_{2}=0.3$, $k=1$ and $\alpha=0.5$. In this case, before the contest interest group $x$ is the underdog, 
$p_{x}^{0}=d_{1} \delta_{1 x}+d_{2} \delta_{2 x}=0.45$. However, since conditions (i) and (ii) are satisfied, $\delta_{1 x}=\frac{4}{7}>\frac{1}{6}=\delta_{2 x}$ and $d_{1} \sqrt{\delta_{1 x} \delta_{1 y}}=0.3464>0.1118=d_{2} \sqrt{\delta_{2 x} \delta_{2 y}}$, interest group $x$ will take part in the contest and increase the probability of the policy $x$ from 0.45 to 0.508 (since in this case, $A=0.1625$ and $B=0.1525, p_{x}=0.508$ ). So the contest can change the identity of the underdog, which means that there is no guarantee that the favorite interest group prior to the contest does not turn to be the underdog when it takes part in the contest.

The above reversal is impossible when the interest groups share equal stakes and both parties are ideologically inclined to the initially favorite interest group $y$. In such a case, if interest group $y$ is effective it becomes even stronger. To sum up, if $p_{x}^{0}<0.5$, then it is possible that interest group $x$ is effective and $p_{x}>0.5>p_{x}^{0}$. However, such reversal in the status of interest group $x$ is impossible when $k=1$ and both $\delta_{1 y}>\delta_{1 x}$ and $\delta_{2 y}>\delta_{2 x} \cdot{ }^{10}$

Theorem 1 relates to interesting phenomenon in the political-economic environment and it can be tested empirically. Let us clarify its relevance and the reason why it is amenable to empirical testing by focusing on the effect of religious and economic extremism on the performance of interest groups.

In certain countries, e.g., Turkey or Israel, a trend of increased religious and economic extremism has been observed. The former phenomenon can be measured by the change in the size or declared norms of the religious population and/or by the change in the preferences of the interest groups that support legislation that is consistent with religious norms. The latter fact can be represented by the change in the income or wealth distribution (the degree of income or wealth inequality) that alters the relative stakes of the rich minority and the poor majority. One may wonder about the effect of these trends on the performance of the interest groups that try to influence the policy outcome in the legislature to be consistent with the norms of the religious minority or fit the goals of the wealthy minority group. In our setting, performance of an interest group can be defined as its success to attain its objectives.

10 In this case $\left(d_{1} \delta_{1 y}\right) \frac{1}{1-\alpha}+\left(d_{2} \delta_{2 y}\right) \frac{1}{1-\alpha}>\left(d_{1} \delta_{1 x}\right) \frac{1}{1-\alpha}+\left(d_{2} \delta_{2 x}\right) \frac{1}{1-\alpha}$, which means that $B>A$ or $p_{x}<0.5$, see (7). 
Theorem 1 sheds light on the effect of extremism as reflected in the power of the parties and their ideological dispositions on the success of a minority interest group in the post-elections contest.

Let us examine now a majoritarian system, with a ruling coalition (party) assuming that party discipline is enforced. With no loss of generality, let the ruling coalition be denoted by 1 . This means that $d_{1}>d_{2}$. In this case, the lobbying efforts of the two interest groups are directed just to the members of coalition (party 1) in order to affect that coalition decision (the enforced line) that becomes the final policy outcome in the legislature. Note that regardless of the size of the positive efforts incurred by the interest groups, an interest group cannot win the contest with certainty; it cannot ensure that an absolute majority of the members of coalition (party 1) vote for its target policy in probability 1 .

In this case the efficacy of an interest group hinges on its relative stake. That is,

Theorem 2: In a majoritarian system with enforced party discipline, interest group $x$ is effective if and only if $k>1$.

The intuition behind this result is that when interest group $x$ has the higher stake, it is induced to invest more than interest group $y$. In turn, it increases its winning probability relative to the case where the two interest groups do not engage in lobbying the members of the ruling coalition (party). Furthermore, if in the absence of a contest interest group $x$ is the underdog, that is, $0.5>p_{x}^{0}=\delta_{1 x}$, where 1 is the ruling coalition, it can become the favorite when it takes part in the lobbying contest, that is, $p_{x}>0.5>p_{x}^{0}=\delta_{1 x}$. Define $\delta=\frac{\delta_{1 x}}{\delta_{1 y}}$ as the ideological bias of 1 to the target policy of interest group $x$. The condition ensuring this reversal is the inequality $k^{\alpha} \delta>1 .^{11}$ The reason is the following: Since, by assumption, 1 is biased in favor of interest group $y$, $\delta_{1 x}<0.5<\delta_{1 y}$ or $\delta<1$, to become a favorite and counterbalance the initial bias in favor of interest group $y$, interest group $x$ has to make more lobbying efforts than interest group $y$ and its required effort is increasing with the initial advantage of $y$.

\footnotetext{
${ }^{11}$ This condition implies that if in the absence of a contest interest group $x$ is the favorite, then its status is unaltered in a contest.
} 
Interest group $x$ has the incentive to make the required effort when $k^{\alpha} \delta>1$. That is, if its relative benefit from winning the contest $k$ and, in turn, $k^{\alpha}$ is sufficiently large.

The analysis of the contest equilibrium under the majoritarian systems under un-enforced and enforced party discipline enables comparison between the winning probabilities of an interest group under the two cases where it directs its lobbying efforts to the members of all the parties or just to the members of the ruling coalition (party). This comparison implies that interest group $x$ prefers to direct its efforts to the members of all the parties (the coalition and opposition parties) if its support in the minority party (block of parties) 2 exceeds that of the majority party (block of parties) 1. That is,

Theorem 3: Interest group $x$ prefers to direct its lobbying efforts to the members of all the parties under un-enforced party discipline rather than lobby just the members of the ruling party (coalition) under enforced party discipline if and only if $\delta_{2 x}>\delta_{1 x}$.

The analysis of contest equilibrium also enables comparison between the total efforts incurred by the interest groups under un-enforced and enforced party discipline. It turns out that aggregate efforts are larger under un-enforced relative to enforced discipline if two conditions are satisfied: First, the balance of incentives is in favor of one of the interest groups both under un-enforced and enforced discipline and, second, the larger ruling party is in favor of that interest group. Formally,

Theorem 4: Let the larger party (block of parties) be denoted by 1. Aggregate efforts are larger under un-enforced relative to enforced discipline if

(i) $k^{\alpha}\left(\frac{A}{B}\right)^{1-\alpha}>1, k^{\alpha} \delta>1$ and $\delta_{2 x}<\delta_{1 x}$,

or

(ii) $k^{\alpha}\left(\frac{A}{B}\right)^{1-\alpha}<1, k^{\alpha} \delta<1$ and $\delta_{2 y}<\delta_{1 y}$.

Aggregate efforts are often used as a welfare criterion in studies of rent dissipation, Typically, they are considered as a measure of the extent of inefficiency associated with the waste implied by at least' part of the lobbying efforts. Theorem 4 thus 
specifies sufficient condition for the welfare superiority of un-enforced party discipline relative to enforced party discipline.

\section{Party characteristics and post-elections contest intensity}

The analysis of contest equilibrium also enables direct examination of the relationship between party characteristics and the post-elections intensity of the contest between the interest groups. The party characteristics, ideological predisposition or heterogeneity and power are represented by the parameters $d_{1}, \delta_{1 x}$ and $\delta_{2 x}\left(d_{2}, \delta_{1 y}\right.$ and $\delta_{2 y}$ are directly obtained from the equalities $d_{1}+d_{2}=1$ and $\delta_{i y}=1-\delta_{i x}$ ). The contest intensity is measured by the amount of resources directed by the contestants to the parties, namely by $\sum_{i=1}^{2} x_{i}+\sum_{i=1}^{2} y_{i}$, see (6). This intensity is important not only because it may give an idea about the size of the lobbying industry, but because it is often considered as a measure of inefficiency.

In the literature on electoral competition, identical and symmetric (neutral) parties often emerge in equilibrium of Downs-type models of the electoral game, Downs (1957), or in equilibrium of electoral competition models with special interest groups, Grossman and Helpman (2001). That is, in our terms, the ideological predispositions or degree of heterogeneity of the parties are identical and both are equally inclined toward the target policies of the two interest groups, $\delta_{1 x}=\delta_{2 x}=0.5$. If such a situation is preserved in the post election phase in the contest on the secondary policy options on which we focus, it implies maximal competition between the parties in the elections which typically results in equal probabilities of winning the elections. By our next result, such symmetric (neutral) identical parties also give rise to maximal intensity of the post-elections contest between interest groups with identical valuations of their target policies, regardless of the post-elections power distribution of the parties. In such contests with maximal intensity, the choice probabilities of the two possible outcomes are equal, that is, $p_{x}=p_{y}=0.5$. In fact, even when $k>1$, identical ideologies are sufficient to give rise to a contest of maximal intensity, regardless of parties' power distribution, provided that $\delta_{1 x}=\delta_{2 x}=\frac{1}{1+k^{\alpha}}$ and $\delta_{1 y}=\delta_{2 y}=\frac{k^{\alpha}}{1+k^{\alpha}}$. That is, provided that the valuation advantage of interest group $x$ is appropriately reduced by the decrease in the support 
of both parties in its target policy $x$, such that the two interest groups become equal competitors that have maximal incentive to invest in the post-elections competition in order to influence the legislature.

Sometimes, however, the equilibrium outcome of the electoral game is such that the platforms of the parties are polarized, Alesina and Rosenthal (2000), FauliOller et.al. (2003), Testa (2010). In our terms, in such cases $\delta_{1 x}=1$ and $\delta_{2 x}=0$, that is, the two parties are extremely homogeneous yet with diametrically opposed ideological dispositions. It turns out that such polarization also results in maximum intensity of the post-elections contests between interest groups with identical valuations of their target policies, provided that the power of the parties is identical. However, the interest groups need not be symmetric. In this more general asymmetric case, ideological polarization results in maximal intensity of the post-elections contest, provided that $d_{1}=\frac{1}{1+k^{\alpha}}$. That is, provided that the valuation advantage of interest group $x$ is appropriately reduced by the decrease in the power of its supporting party (party 1), such that the two interest groups become equal competitors that have maximal incentive to invest in the post-elections competition in order to influence the legislature. ${ }^{12}$ Formally,

Theorem 5: If (a) $\delta_{1 x}=\delta_{2 x}=\frac{1}{1+k^{\alpha}}$ and $\delta_{1 y}=\delta_{2 y}=\frac{k^{\alpha}}{1+k^{\alpha}}$, or (b) $\delta_{1 x}=1$ and $\delta_{2 x}=0$ and $d_{1}=\frac{1}{1+k^{\alpha}}$, then the efforts directed by the interest groups to the parties are maximal and equal to $0.25 \alpha\left(n_{x}+n_{y}\right)$ and $p_{x}=p_{y}=0.5$.

Clearly, by Theorem 5, if $k=1$ and $\delta_{1 x}=\delta_{2 x}=0.5$, that is, the parties are identical and symmetric (neutral), or $\delta_{1 x}=1, \delta_{2 x}=0$, and the parties have equal power, $d_{1}=d_{2}=0.5$, then, in both cases, the efforts of the interest groups are maximal and equal to $0.5 \alpha n$, where $n=n_{x}=n_{y}$. Note that by Theorem 5 , the maximal efforts are

\footnotetext{
${ }^{12}$ Several studies focusing on the question how a contest should be designed to yield maximum efforts obtained similar results that stress the significance of equalizing the actual strength of the contestants. See, for example, Epstein et al. (2011) who deal with two-player contests where the contest designer will optimally equalize the contestants' strength and Franke et al. (2011) who examine $n$-player contests where the designer will optimally level the playing field by encouraging weak contestants, but not equalize the contestants' chances unless they are identical.
} 
increasing in the valuations of the interest groups, $n_{x}$ and $n_{y}$, and in the parameter $\alpha$. However, they are independent of $k$, the asymmetry between the valuations of the interest groups. According to part (a) (part (b)) of Theorem 5, although $k$ requires appropriate counter asymmetry in terms of the parties' ideological (power) support in the target policy $x$ - asymmetry against interest group $x$, in order to ensure the maximal intensity of the contest, it does not affect the value of the maximal efforts of the interest groups. ${ }^{13}$

The results derived in this section provide a simple possible rationale for the different intensity of lobbying efforts in European parliamentary legislatures relative to the American legislature with low-voting cohesion. The general necessary and sufficient condition for maximal intensity of the contest between the interest groups is:

$$
k^{\alpha}\left(\frac{A}{B}\right)^{1-\alpha}=1,
$$

(see A.1 in the proof of Theorem 5), that is, equality of the incentives of the two interest groups $n_{x}^{\alpha} A^{1-\alpha}$ and $n_{y}^{\alpha} B^{1-\alpha}$. These incentives depend on the interest groups' valuation of their target policies, on the parties' support of these target policies and on the power of the two parties. Usually the incentives of the interest groups are not equal, the contestants' efforts are not maximal and the interest group with the larger incentive exerts more efforts than its rival. When the difference between the incentives of the interest groups is increased their efforts decline. This is the reason why the lobbying efforts in the European legislature are weaker than the lobbying efforts in the American legislature; the parties in the former are less symmetric in terms of ideological predispositions and power than the latter and consequently the gap between the incentives of the interest groups in Europe is larger than the gap between the interest groups' incentives in the US. ${ }^{14}$ Theorem 5 implies that the incentives of interest groups within a particular state are directly correlated with their lobbying efforts. It also implies that the gap between the incentives of interest groups

\footnotetext{
${ }^{13}$ Notice that in our setting no constraints are imposed on the lobbying efforts of the interest groups as, for example, in Che and Gale (1998) or Iaryczower and Mattozzi (2012). This assumption might be plausible when the capital market is perfect or when the stakes are sufficiently small. For a discussion on the equivalence between the effect of budget constraints and the effect of regulation, see Che and Gale (1997).

${ }^{14}$ For a different rationale, which is proposed using an informational lobbying model, see Bennedsen and Feldmann (2002).
} 
in different states is inversely correlated with the aggregate lobbying efforts in these states. Theorem 5 can therefore be very useful in explaining the observed difference of lobbying efforts of interest groups within particular states and in explaining the observed difference between aggregate lobbying efforts in different states.

\section{Intensity and efficacy of the contestants}

Given the conditions ensuring efficacy of an interest group and the conditions that ensure maximal intensity of the contest between the interest groups, the question is whether these separate conditions are interrelated. In particular, are these conditions interrelated in such a way that maximal contest intensity implies universal inefficacy in which no interest group can be effective? Does efficacy imply that the contestants' efforts are less than maximal? In general, both conjectures are false. When the contestants' efforts are maximal, it is possible that one of the interest groups is effective or that both interest groups are not effective. To prove this claim, let us present two examples that illustrate the two possibilities.

Example 2: Consider the case of identical neutral parties of equal strength and symmetric interest groups, that is, $k=1$ and $\delta_{1 x}=\delta_{2 x}=d_{1}=d_{2}=0.5$. In such a case no interest group is effective because $p_{x}^{0}=d_{1} \delta_{1 x}+d_{2} \delta_{2 x}=p_{x}=0.5$. Notice that although $p_{x}^{0}=0.5$, the interest groups have an incentive to participate in a contest that does not affect their initial situation in terms of $p_{x}$ and $p_{y}$, yet reduces their payoff because of their maximal expended efforts.

Example 3: Suppose that the contestants' efforts are maximal and let $k=1, \delta_{1 x}=\frac{4}{7}$, $\delta_{1 y}=\frac{3}{7}, \delta_{2 x}=\frac{1}{6}, \delta_{2 y}=\frac{5}{6}$ and $\alpha=0.5$. The sufficient condition for maximal efforts implies that $d_{1}=\frac{14-\sqrt{42}}{11}$ and $d_{2}=\frac{\sqrt{42}-3}{11} \cdot{ }^{15}$ In such a case, $p_{x}=0.5$, yet $d_{1} \delta_{1 x}+d_{2} \delta_{2 x}<0.5=p_{x}$. That is, interest group $x$ is effective.

15 The sufficient condition is: $k^{\frac{\alpha}{1-\alpha}}\left[\frac{\left(d_{1} \delta_{1 x}\right) \frac{1}{1-\alpha}+\left(d_{2} \delta_{2 x}\right) \frac{1}{1-\alpha}}{\left(d_{1} \delta_{1 y}\right)^{\frac{1}{1-\alpha}}+\left(d_{2} \delta_{2 y}\right) \frac{1}{1-\alpha}}\right]=1$. For a proof, see the proof of Theorem 5 (part a) in the Appendix. 
To sum up, maximal contest intensity may, but need not eliminate the possible existence of efficacy even when the interest groups are symmetric, $k=1$. For such interest groups, we are able to completely characterize the situations where efforts are maximal yet no interest group is effective. In such situations it is impossible to have parties that are not symmetric either in terms of power or in terms of their ideological predisposition toward the target policies of the interest groups. Some symmetry is necessary. Formally,

Remark: Let $k=1$. If efforts are maximal and no interest group is effective, then one of the following possibilities must hold:

1. Regardless of the power distribution of the parties, they must be neutral and identical, that is, $\delta_{1 x}=\delta_{2 x}=\delta_{1 y}=\delta_{2 y}=0.5$.

2. $d_{1}=d_{2}=0.5, \delta_{1 x}=\delta_{2 y}$ and $\delta_{1 y}=\delta_{2 x}$. That is, the parties are equal in power and the predisposition of one party toward the target policy of one interest group is equal to the inclination of the other party toward the target policy of the other interest group.

Again, as in Example 2, under such situations the symmetric interest groups would participate most actively in a contest that does not affect their target policy and therefore only reduces their net payoffs.

\section{Efforts sensitivity to ideological heterogeneity, political power and valuations}

To examine the sensitivity of the contestants' efforts to changes in the characteristics of the parties and the interest groups' valuation of their target policies, let us reintroduce the general necessary and sufficient condition for maximal intensity of the contest between the interest groups. This condition,

$$
k^{\alpha}\left(\frac{A}{B}\right)^{1-\alpha}=1,
$$

(again, see A.1 in the proof of Theorem 5), requires complete leveling of the playing field, that is, equality of the incentives of the two interest groups. That is, $n_{x}^{\alpha} A^{1-\alpha}=n_{y}^{\alpha} B^{1-\alpha}$. Suppose that the incentives of the interest groups are not equal. In such a case, any change in the characteristics of the parties that tends to restore 
(further upset) the balance of incentives between the interest groups increases (reduces) the intensity of the contest; the efforts directed to the parties. If the incentives of the interest groups are equal, then any change in the characteristics of the parties that upsets the balance of incentives between the interest groups will reduce their efforts. Relating to changes of specific parameters, that is, changes in the power of the parties or in their heterogeneity, we obtain the following corollaries of this general result.

\subsection{Efforts and changes in ideological heterogeneity}

\section{Theorem 6.1:}

(a) Under un-enforced discipline, the efforts of the interest groups (separately and jointly) are positively related to a change in $\delta_{j x}$ (in $\delta_{j y}$, if and only if $k^{\alpha}\left(\frac{A}{B}\right)^{1-\alpha}<1$ $\left(k^{\alpha}\left(\frac{A}{B}\right)^{1-\alpha}>1\right)$

(b) If $k^{\alpha}\left(\frac{A}{B}\right)^{1-\alpha}=1$, then any change in $\delta_{j x}$ or $\delta_{j y}$ reduces the efforts of the interest groups.

That is, if the balance of incentives is in favor of interest group $y$, that is, $k^{\alpha}\left(\frac{A}{B}\right)^{1-\alpha}<1$, then an increase of the ideological support of a party in interest group $x$, which tends to restore the balance, increases the efforts of the interest groups. If the interest groups are of equal incentives, then upsetting the balance between them by a change in the heterogeneity of any party reduces the contestants' efforts.

\subsection{Efforts and changes in political power}

Theorem 6.2 : Under un-enforced discipline,

(a) the efforts of the interest groups (separately and jointly) are positively related to a change in $d_{1}$, if and only if $\left[1-k^{\alpha}\left(\frac{A}{B}\right)^{1-\alpha}\right]\left(\delta_{2 y}-\delta_{1 y}\right)>0$. 
(b) if $k^{\alpha}\left(\frac{A}{B}\right)^{1-\alpha}=1$, then any change in the power of the parties reduces the efforts of the interest groups.

That is, if the balance of incentives is in favor of interest group $x$ (interest group $y$ ), that is, $k^{\alpha}\left(\frac{A}{B}\right)^{1-\alpha}>1\left(k^{\alpha}\left(\frac{A}{B}\right)^{1-\alpha}<1\right)$, then an increase in the power of a party that is inclined toward the target policy of the other interest group $y$ (interest group $x$ ), which tends to restore the balance, increases the efforts of the contestants. If the interest groups have equal incentives, then upsetting the balance between them by a change in the power distribution of the parties reduces the contestants' efforts.

\subsection{Efforts and changes in valuations}

Theorem 6.3.: Under un-enforced discipline,

(a) the total efforts of the interest groups are positively related to a change in $n_{x}$ if $k^{\alpha}\left(\frac{A}{B}\right)^{1-\alpha}<1$ and positively related to a change in $n_{y}$ if $k^{\alpha}\left(\frac{A}{B}\right)^{1-\alpha}>1$.

(b) if $k^{\alpha}\left(\frac{A}{B}\right)^{1-\alpha}=1$, then any mean-preserving change in the valuation of the target policies of the interest groups reduces their total efforts.

(C) if $k^{\alpha}\left(\frac{A}{B}\right)^{1-\alpha}=1$, then any $k$-preserving change in the valuation of the target policies of the interest groups positively affects their total efforts.

That is, by part (a), when a change in an interest group's valuation of its target policy tends to reduce the imbalance between the interest groups, both interest groups behave more aggressively and increase their efforts. By part (b), if the interest groups have equal incentives, then upsetting the balance between them by a mean preserving change in $n_{x}$ and $n_{y}$ (that is, $\left(n_{x}+n_{y}\right)$ is unchanged) reduces the contestants' total efforts. A similar result has been established in the rent-seeking literature assuming a Tullock (1980) type lottery. Namely, total rent-seeking efforts are reduced when the 
contestants differ more in their valuation of the prize, see Nti (1999) and Konrad (2009, Ch 2.3). Finally, by part (c), if the interest groups have equal incentives, then increasing (decreasing) both $n_{x}$ and $n_{y}$ such that $k$ is unchanged, increases (reduces) the contestants' total efforts.

Theorem 6 can also be used to shed light on observed changes in the extent of lobbying along time in certain states in response to changes in the characteristics of the parties or in the gap between the interest groups' valuation of their target policies. Undoubtedly the extent of lobbying has increased substantially in many countries. In the context of the religious and economic extremism discussed in Section 4, or in the context of extremism related to migration policy or reform in the pension system, Theorems 6 can clarify the effect of extremism on the exerted lobbying efforts in the post-elections phase. In particular, over time, with the increase of migration to Europe and other places in the world, the local populations developed xenophobia as they have become more afraid to lose their identity and culture. Political parties and interest groups that attempt to decrease migration have become stronger, more extreme and more active. The relationship between the observed activity of interest groups and their performance and the change in the parameters of the model that represent extremism of parties and/or interest groups can be better understood in light of the above comparative-statics results.

The comparative statics results under enforced party discipline are unaltered. The reason is that when $d_{1}=1$ and $d_{2}=0$ (recall that 1 is the larger ruling party, instead of $\left(\frac{A}{B}\right)^{1-\alpha}=\delta$ we get $\left.k^{\alpha} \delta=1\right)$.

\section{Conclusion}

Given the post-elections political environment, which is represented herein by the actual power of the two parties and by their ideological predispositions, we have initially focused on the (necessary and sufficient) conditions for the success of a specialized interest group to enhance its objective, namely, to increase the probability that the policy consistent with its interest is realized. By our first result, under unenforced party discipline, ideological proximity to a party and the dominance of that party in terms of degree of heterogeneity weighted by political power ensure the efficacy of an interest group. This result has two clear implications. 
(i) A successful interest group need not be "closer" to the stronger party. In such a case, however, the closer party must be sufficiently heterogeneous: namely, allow a large number of members to share the two different ideological views.

(ii) A successful interest group need not be "closer" to the more heterogeneous party. In such a case, however, the closer party must be sufficiently strong.

We have also established the possible reversal of the interest groups' status (becoming a favorite instead of an underdog) which occurs due to their participation in the contest and provided a sufficient condition that precludes such reversal.

By our second result, under enforced party discipline, interest group $x$ is effective if and only if it has the higher benefit from winning the contest $(k>1)$. Again, even in this case a reversal of the status of an interest group (becoming a favorite) is possible provided that its stake in the contest is sufficiently large relative to that of its opponent. We have then established in the third result that interest group $x$ prefers to direct its lobbying efforts to the members of all the parties under unenforced party discipline rather than lobby just the members of the ruling party (coalition) under enforced party discipline, if and only if its support in the minority party (block of parties) exceeds that of the majority party (block of parties). We have also shown in the fourth result that aggregate efforts are larger under un-enforced relative to enforced discipline, if the balance of incentives is in favor of one of the interest groups both under un-enforced and enforced discipline and the larger ruling party (coalition) is in favor of that interest group.

The equilibrium analysis of our single-stage, two-player (interest group) postelections contest enables the study of the relationship between party characteristics (degree of heterogeneity and power) and the intensity of the contest between the interest groups. By the first part of our fifth result, identical neutral parties give rise to maximum intensity of the post-elections contest between interest groups with identical valuations of their target policies. This result is robust to the post-elections power distribution of the parties. In such contests of maximal intensity, the equilibrium expected policy outcome in the legislature is balanced. That is, the choice probabilities of the target policies of the interest groups are equal. In the second part of the second result, we have provided conditions that ensure that polarized parties give rise to contests with maximal intensity. Such polarization together with equal power of the parties and identical interest groups' valuations of their target policies are sufficient conditions for the maximization of efforts by the interest groups. 
Interestingly, when maximal resources are directed by the interest groups to the parties, the value of the resources is independent of the valuation asymmetry between the contestants. This is due to the fact that in such situations the asymmetry between the contestants is cancelled out either by the balancing asymmetry in the power of the parties or by the balancing asymmetry in the support that the two parties give to the two interest groups. We then examined the possibility of coexistence of maximal intensity of the contest between the interest groups and no efficacy of any group. For the case of symmetric interest groups, we characterized the situations of such coexistence. In such cases some symmetry is necessary: either symmetry and neutrality of the ideologies of the parties or equality of power of the parties and similar proximity of their possibly different ideologies to the target policies of the different interest groups. We have also examined the sensitivity of the efforts of the interest groups (separately and jointly) to changes in the contest parameters (the power and ideological heterogeneity of the parties and the contestants' stakes). By the last result, if the playing field is not completely leveled, that is, incentives of the interest groups are not equal, then any change in the characteristics of the parties that increases (reduces) the balance of incentives between the interest groups increases (reduces) the intensity of the contest (the efforts directed to the parties).

Finally note that the generalization of our setting to more than two parties is possible without affecting the results. However, the generalization of the two interest group contest to an $n$-player contest is a challenging task that deserves future attention and the results may not be robust to such generalization.

\section{References}

Alesina, A.F. and Rosenthal, H., 2000, Polarized platforms and moderate policies with checks and balances, Journal of Public Economics, 75(1),

Baron, D.P., 2006, Competitive lobbying and supermajorities in a majority-rule institution, Scandinavian Journal of Economics, 108(4), 607-642

Becker, G., 1983, A Theory of competition among pressure groups for political influence, Quarterly Journal of Economics, 98(3), 371-400.

Bennedsen, M. and Feldmann, S.E., 2002, Lobbying legislatures, Journal of Political Economy,110(4), 919-946. 
Che, Y.K. and Gale, I., 1997, Rent seeking when rent sekers are budget constrained, Public Chopice, 92, 109-126.

Che, Y.K. and Gale, I., 1998, Caps on political lobbying, American Economic Review, 88, 643-651.

Coughlin, P. and Nitzan, S., 1981, Electoral outcomes with probabilistic voting and Nash social welfare maxima, Journal of Public Economics, 15, 113-21.

Clark, D.J. and Riis, C., 1998, Contest success functions: An extension. Economic Theory, 11, 201-204.

Downs, A., 1957, An Economic Theory of Democracy, Harper and Row, New York.

Dixit, A., 1987, Strategic behavior in contests. American Economic Review, 77, 891898.

Epstein, G.S., Mealem, Y. and Nitzan, S., 2011, Political culture and discrimination in contests, Journal of Public Economics, 95, 88-93.

Epstein, G.S. and Nitzan, S., 2007, Endogenous Public Policy and Contests, SpringerVerlag, Heidelberg.

Fauli-Oller, Ok, E.A. and Ortuño-Ortin, I., 2003, Delegation and polarization of platforms, Economic Theory, 22(2), 289-309.

Franke J. , Kanzow C. Leininger W. and Schwartz A., 2011, "Effort maximization in asymmetric contest games with heterogeneous contestants", Economic Theory, forthcoming.

Grossman, G.M. and Helpman, E., 2001, Special Interest Politics, MIT Press, Cambridge, MA.

Iaryczower, M. and Mazzotti, A., 2012, The pro-competitive effect of campaign limits in non-majoritarian elections, Economic Theory, 49(3), 591-619.

Intriligator, M., 1973, A probabilistic model of social choice, Review of Economic Studies, 40 (4), 553-560.

Konrad, K., 2009, Strategy and Dynamics in Contests (London School of Economic Perspectives in Economic Analysis), Oxford University Press, USA.

Nti, K.O., 1999, Rent seeking with asymmetric valuations. Public Choice, 98, 415430.

Skaperda, S. and Vaidya, S., 2009, Persuasion as a contest, Economic Theory, forthcoming.

Testa, C., 2010, Party polarization and electoral accountability, memo (revised version of Royal Holloway Discussion Paper Series, dpe03/013). 
Tullock, G., 1980, Efficient rent-seeking. In Buchanan, J.M., Tollison, R.D. and

Tullock, G. 1980, Toward a Theory of the Rent-Seeking Society. (College Station: Texas A. and M. University Press, 97-112).

Winden, van F., 1999, On the economic theory of interest groups: Towards a group frame of reference in political economics. Public Choice, 100, 1-29.

Wittman, D., 2009, How pressure groups activate voters and move candidates closer to the median" Economic Journal 119, (540), 1324-1343.

\section{Appendix}

Proof of Theorem 1: An interest group's participation $x$ in the contest is effective if:

$$
p_{x}=\frac{k^{\alpha}\left(\frac{A}{B}\right)^{1-\alpha}}{k^{\alpha}\left(\frac{A}{B}\right)^{1-\alpha}+1}>d_{1} \delta_{1 x}+d_{2} \delta_{2 x}=p_{x}^{0}
$$

That is,

$$
k^{\alpha}\left(\frac{A}{B}\right)^{1-\alpha}\left[1-\left(d_{1} \delta_{1 x}+d_{2} \delta_{2 x}\right)\right]>d_{1} \delta_{1 x}+d_{2} \delta_{2 x}
$$

or

$$
k^{\alpha}\left(\frac{A}{B}\right)^{1-\alpha}\left(d_{1} \delta_{1 y}+d_{2} \delta_{2 y}\right)>d_{1} \delta_{1 x}+d_{2} \delta_{2 x}
$$

or

$$
k^{\alpha}\left[\frac{\left(d_{1} \delta_{1 x}\right)^{\frac{1}{1-\alpha}}+\left(d_{2} \delta_{2 x}\right)^{\frac{1}{1-\alpha}}}{\left(d_{1} \delta_{1 y}\right)^{\frac{1}{1-\alpha}}+\left(d_{2} \delta_{2 y}\right)^{\frac{1}{1-\alpha}}}\right]^{1-\alpha}>\frac{d_{1} \delta_{1 x}+d_{2} \delta_{2 x}}{d_{1} \delta_{1 y}+d_{2} \delta_{2 y}}
$$

or

$$
k^{\frac{\alpha}{1-\alpha}}\left[\frac{\left(d_{1} \delta_{1 x}\right)^{\frac{1}{1-\alpha}}+\left(d_{2} \delta_{2 x}\right)^{\frac{1}{1-\alpha}}}{\left(d_{1} \delta_{1 y}\right)^{\frac{1}{1-\alpha}}+\left(d_{2} \delta_{2 y}\right)^{\frac{1}{1-\alpha}}}\right]>\left(\frac{d_{1} \delta_{1 x}+d_{2} \delta_{2 x}}{d_{1} \delta_{1 y}+d_{2} \delta_{2 y}}\right)^{\frac{1}{1-\alpha}}
$$

Define $\beta=\frac{1}{1-\alpha}>1$. Then the condition becomes: ${ }^{16}$

\footnotetext{
${ }^{16} \mathrm{We}$ are indebted to Jonathan Stupp for his help in establishing this part of the proof.
} 


$$
k^{\frac{\alpha}{1-\alpha}}\left[\frac{\left(d_{1} \delta_{1 x}\right)^{\beta}+\left(d_{2} \delta_{2 x}\right)^{\beta}}{\left(d_{1} \delta_{1 y}\right)^{\beta}+\left(d_{2} \delta_{2 y}\right)^{\beta}}\right]>\left(\frac{d_{1} \delta_{1 x}+d_{2} \delta_{2 x}}{d_{1} \delta_{1 y}+d_{2} \delta_{2 y}}\right)^{\beta}
$$

or

$$
k^{\frac{\alpha}{1-\alpha}}\left[\frac{\left(d_{1} \delta_{1 x}\right)^{\beta}+\left(d_{2} \delta_{2 x}\right)^{\beta}}{\left(d_{1} \delta_{1 y}\right)^{\beta}+\left(d_{2} \delta_{2 y}\right)^{\beta}}\right] \frac{\left(d_{1} \delta_{1 y}\right)^{\beta}}{\left(d_{1} \delta_{1 x}\right)^{\beta}}>\left(\frac{d_{1} \delta_{1 x}+d_{2} \delta_{2 x}}{d_{1} \delta_{1 y}+d_{2} \delta_{2 y}}\right)^{\beta} \frac{\left(d_{1} \delta_{1 y}\right)^{\beta}}{\left(d_{1} \delta_{1 x}\right)^{\beta}}
$$

or

$$
k^{\frac{\alpha}{1-\alpha}}\left[\frac{\frac{\left(d_{1} \delta_{1 x}\right)^{\beta}+\left(d_{2} \delta_{2 x}\right)^{\beta}}{\left(d_{1} \delta_{1 x}\right)^{\beta}}}{\frac{\left(d_{1} \delta_{1 y}\right)^{\beta}+\left(d_{2} \delta_{2 y}\right)^{\beta}}{\left(d_{1} \delta_{1 y}\right)^{\beta}}}\right]>\left[\left(\frac{d_{1} \delta_{1 x}+d_{2} \delta_{2 x}}{d_{1} \delta_{1 y}+d_{2} \delta_{2 y}}\right) \frac{d_{1} \delta_{1 y}}{d_{1} \delta_{1 x}}\right]^{\beta}
$$

or

$$
k^{\frac{\alpha}{1-\alpha}}\left[\frac{1+\left(\frac{d_{2} \delta_{2 x}}{d_{1} \delta_{1 x}}\right)^{\beta}}{1+\left(\frac{d_{2} \delta_{2 y}}{d_{1} \delta_{1 y}}\right)^{\beta}}\right]>\left(\frac{\frac{d_{1} \delta_{1 x}+d_{2} \delta_{2 x}}{d_{1} \delta_{1 x}}}{\frac{d_{1} \delta_{1 y}+d_{2} \delta_{2 y}}{d_{1} \delta_{1 y}}}\right)^{\beta}
$$

or

$$
k^{\frac{\alpha}{1-\alpha}}\left[\frac{1+\left(\frac{d_{2} \delta_{2 x}}{d_{1} \delta_{1 x}}\right)^{\beta}}{1+\left(\frac{d_{2} \delta_{2 y}}{d_{1} \delta_{1 y}}\right)^{\beta}}\right]>\left(\frac{1+\frac{d_{2} \delta_{2 x}}{d_{1} \delta_{1 x}}}{1+\frac{d_{2} \delta_{2 y}}{d_{1} \delta_{1 y}}}\right)^{\beta}
$$

Define $z=\frac{d_{2} \delta_{2 x}}{d_{1} \delta_{1 x}}$ and $w=\frac{d_{2} \delta_{2 y}}{d_{1} \delta_{1 y}}$. Then the last inequality becomes:

$$
\begin{aligned}
& k^{\frac{\alpha}{1-\alpha}}\left(\frac{1+z^{\beta}}{1+w^{\beta}}\right)>\left(\frac{1+z}{1+w}\right)^{\beta} \\
& k^{\frac{\alpha}{1-\alpha}}\left[\frac{1+z^{\beta}}{(1+z)^{\beta}}\right]>\frac{1+w^{\beta}}{(1+w)^{\beta}}
\end{aligned}
$$

In order to check when the last condition is satisfied, define $f(a)=\frac{1+a^{\beta}}{(1+a)^{\beta}}$ and let's find the extreme values: 


$$
\begin{gathered}
\frac{d f(a)}{d a}=\frac{\beta a^{\beta-1}(1+a)^{\beta}-\beta(1+a)^{\beta-1}\left(1+a^{\beta}\right)}{(1+a)^{2 \beta}}=0 \\
\frac{d f(a)}{d a}=\frac{\beta(1+a)^{\beta-1}\left[a^{\beta-1}(1+a)-\left(1+a^{\beta}\right)\right]}{(1+a)^{2 \beta}}=0 \\
\frac{d f(a)}{d a}=\frac{\beta(1+a)^{\beta-1}\left(a^{\beta-1}-1\right)}{(1+a)^{2 \beta}}=0 \\
a=1
\end{gathered}
$$

and the second order condition reveals that at $a=1, f$ has a minimum point (recall that $\beta>1)$ :

$$
\frac{d^{2} f(a)}{d a^{2}}=2^{\beta-1} \beta(\beta-1)>0
$$

This means that in the range $0<a<1, f(a)$ decreases and in the range $a>1$ it increases. Without loss of generality, let $k \geq 1$, and $k^{\alpha} f(z)=k^{\alpha}\left[\frac{1+z^{\beta}}{(1+z)^{\beta}}\right]>\frac{1+w^{\beta}}{(1+w)^{\beta}}=f(w)$ if $f(z)>f(w)$. Therefore, if $k \geq 1$ then $f(z)>f(w)$ is a sufficient condition, whereas if $k=1$ this condition is sufficient and necessary. Since $f(a)=f\left(\frac{1}{a}\right), f(z)>f(w)$ if and only if $z>w>\frac{1}{z}$ (which means that $z>1$ ) or $\frac{1}{z}>w>z$ (which means that $z<1$ ). Consider the first condition $z>w>\frac{1}{z}$. Setting $\quad z=\frac{d_{2} \delta_{2 x}}{d_{1} \delta_{1 x}} \quad$ and $\quad w=\frac{d_{2} \delta_{2 y}}{d_{1} \delta_{1 y}} \quad$ in $\quad z>w>\frac{1}{z}, \quad$ yields: $\frac{d_{2} \delta_{2 x}}{d_{1} \delta_{1 x}}>\frac{d_{2} \delta_{2 y}}{d_{1} \delta_{1 y}}>\frac{d_{1} \delta_{1 x}}{d_{2} \delta_{2 x}}$. From $\frac{d_{2} \delta_{2 x}}{d_{1} \delta_{1 x}}>\frac{d_{2} \delta_{2 y}}{d_{1} \delta_{1 y}}$ we get $\delta_{2 x}>\delta_{1 x}$ (therefore $\delta_{2 y}<\delta_{1 y}$ ) and from $\frac{d_{2} \delta_{2 y}}{d_{1} \delta_{1 y}}>\frac{d_{1} \delta_{1 x}}{d_{2} \delta_{2 x}}$ we get $d_{2} \sqrt{\delta_{2 x} \delta_{2 y}}>d_{1} \sqrt{\delta_{1 x} \delta_{1 y}}$. The results from the second condition, $\frac{1}{z}>w>z$, are the same just the roles of the two parties are reversed

To sum up, the interest group $x$ is effective if there exists a party $i$, such that $\delta_{i x}>\delta_{j x}$ and $d_{i} \sqrt{\delta_{i x} \delta_{i y}}>d_{j} \sqrt{\delta_{j x} \delta_{j y}}$.

\section{Proof of Theorem 2:}


Substituting $d_{1}=1$ and $d_{2}=0$ in equations (1) and (4) - (7), we get that in this case, $A=\delta_{1 x} \frac{1}{1-\alpha}$ and $B=\delta_{1 y} \frac{1}{1-\alpha}$, the efforts of the interest groups in the members of party 1 are $x_{1}=\frac{\alpha n_{x} k^{\alpha} \delta}{\left(k^{\alpha} \delta+1\right)^{2}}$ and $y_{1}=\frac{\alpha n_{y} k^{\alpha} \delta}{\left(k^{\alpha} \delta+1\right)^{2}}$ and the winning probability of interest group $x$ is $p_{x}=\frac{k^{\alpha} \delta}{k^{\alpha} \delta+1}$, where $\delta=\frac{\delta_{1 x}}{\delta_{1 y}}$ is the ideological bias of party 1 to the target policy of interest group $x$. Hence, interest group $x$ is effective if $p_{x}=\frac{k^{\alpha} \delta}{k^{\alpha} \delta+1}>\delta_{1 x}=p_{x}^{0}$. By the proof of Theorem 1, the inequality $p_{x}>p_{x}^{0}$ is equivalent to $k^{\frac{\alpha}{1-\alpha}}\left(\frac{1+z^{\beta}}{1+w^{\beta}}\right)>\left(\frac{1+z}{1+w}\right)^{\beta}$, where $z=\frac{d_{2} \delta_{2 x}}{d_{1} \delta_{1 x}}$ and $w=\frac{d_{2} \delta_{2 y}}{d_{1} \delta_{1 y}}$. Since in our case, $d_{1}=1$ and $d_{2}=0, \quad z=w=0$. Substituting in $k^{\frac{\alpha}{1-\alpha}}\left(\frac{1+z^{\beta}}{1+w^{\beta}}\right)>\left(\frac{1+z}{1+w}\right)^{\beta}$ therefore yields that $p_{x}>p_{x}^{0}$ iff $k>1$.

\section{Proof of Theorem 3:}

In equation (7), the term $\left(\frac{A}{B}\right)^{1-\alpha}$ changes to $\delta$ when we move from the case of a twoparty system with un-enforced party discipline to the case of a majoritarian system with a single ruling party under enforced party discipline. That is, in the latter case $p_{x}=\frac{k^{\alpha} \delta}{k^{\alpha} \delta+1}$. Since $\frac{\partial p_{x}}{\partial \delta}>0$, interest group $x$ will prefer the two-party system with unenforced party discipline provided that $\left(\frac{A}{B}\right)^{1-\alpha}>\delta$ or

$$
\left[\frac{\left(d_{1} \delta_{1 x}\right)^{\frac{1}{1-\alpha}}+\left(d_{2} \delta_{2 x}\right)^{\frac{1}{1-\alpha}}}{\left(d_{1} \delta_{1 y}\right)^{\frac{1}{1-\alpha}}+\left(d_{2} \delta_{2 y}\right)^{\frac{1}{1-\alpha}}}\right]^{1-\alpha}>\frac{\delta_{1 x}}{\delta_{1 y}}
$$

or

$$
\frac{\left(d_{1} \delta_{1 x}\right)^{\frac{1}{1-\alpha}}+\left(d_{2} \delta_{2 x}\right)^{\frac{1}{1-\alpha}}}{\left(d_{1} \delta_{1 y}\right)^{\frac{1}{1-\alpha}}+\left(d_{2} \delta_{2 y}\right)^{\frac{1}{1-\alpha}}}>\left(\frac{\delta_{1 x}}{\delta_{1 y}}\right)^{\frac{1}{1-\alpha}}
$$

or 


$$
\left(d_{1} \delta_{1 x} \delta_{1 y}\right)^{\frac{1}{1-\alpha}}+\left(d_{2} \delta_{2 x} \delta_{1 y}\right)^{\frac{1}{1-\alpha}}>\left(d_{1} \delta_{1 x} \delta_{1 y}\right)^{\frac{1}{1-\alpha}}+\left(d_{2} \delta_{1 x} \delta_{2 y}\right)^{\frac{1}{1-\alpha}}
$$

or

$$
\delta_{2 x} \delta_{1 y}>\delta_{1 x} \delta_{2 y} \text { or } \delta_{2 x}\left(1-\delta_{1 x}\right)>\delta_{1 x}\left(1-\delta_{2 x}\right)
$$

or

$$
\delta_{2 x}>\delta_{1 x}
$$

\section{Proof of Theorem 4 :}

Larger efforts under un-enforced party discipline means that

$$
\sum_{i=1}^{2} x_{i}+\sum_{i=1}^{2} y_{i}=\frac{\alpha k^{\alpha}\left(n_{x}+n_{y}\right)\left(\frac{A}{B}\right)^{1-\alpha}}{\left[k^{\alpha}\left(\frac{A}{B}\right)^{1-\alpha}+1\right]^{2}}>\frac{\alpha k^{\alpha}\left(n_{x}+n_{y}\right) \delta}{\left(k^{\alpha} \delta+1\right)^{2}}=x_{1}+y_{1}
$$

or

$$
\frac{\left(\frac{A}{B}\right)^{1-\alpha}}{\left[k^{\alpha}\left(\frac{A}{B}\right)^{1-\alpha}+1\right]^{2}}>\frac{\delta}{\left(k^{\alpha} \delta+1\right)^{2}}
$$

or, after simplification

$$
\left[k^{2 \alpha} \delta\left(\frac{A}{B}\right)^{1-\alpha}-1\right]\left[\delta-\left(\frac{A}{B}\right)^{1-\alpha}\right]>0
$$

This inequality is satisfied when the two multiplied expressions are either positive or negative. Note that $\left(\frac{A}{B}\right)^{1-\alpha}<\delta$ if and only if $\delta_{2 x}<\delta_{1 x}$. We thus get that the efforts under unenforced party discipline are larger than those enforced discipline if:

(i) $k^{\alpha}\left(\frac{A}{B}\right)^{1-\alpha}>1, k^{\alpha} \delta>1$ and $\delta_{2 x}<\delta_{1 x}$,

or

(ii) $k^{\alpha}\left(\frac{A}{B}\right)^{1-\alpha}<1, k^{\alpha} \delta<1$ and $\delta_{2 y}<\delta_{1 y}$.

Proof of Theorem 5 part (a): Since (see (5) and (6)): 


$$
\sum_{i=1}^{2} x_{i}=\alpha n_{x} \frac{k^{\alpha}\left(\frac{A}{B}\right)^{1-\alpha}}{\left[k^{\alpha}\left(\frac{A}{B}\right)^{1-\alpha}+1\right]^{2}}, \quad \sum_{i=1}^{2} y_{i}=\alpha n_{y} \frac{k^{\alpha}\left(\frac{A}{B}\right)^{1-\alpha}}{\left[k^{\alpha}\left(\frac{A}{B}\right)^{1-\alpha}+1\right]^{2}}
$$

and

$$
\sum_{i=1}^{2} x_{i}+\sum_{i=1}^{2} y_{i}=\alpha\left(n_{x}+n_{y}\right) \frac{k^{\alpha}\left(\frac{A}{B}\right)^{1-\alpha}}{\left[k^{\alpha}\left(\frac{A}{B}\right)^{1-\alpha}+1\right]^{2}},
$$

when $h=\frac{k^{\alpha}\left(\frac{A}{B}\right)^{1-\alpha}}{\left[k^{\alpha}\left(\frac{A}{B}\right)^{1-\alpha}+1\right]^{2}}$ is maximal, $\sum_{i=1}^{2} x_{i}, \sum_{i=1}^{2} y_{i}$ and $\sum_{i=1}^{2} x_{i}+\sum_{i=1}^{2} y_{i}$ are maximal.

A necessary condition for the maximization of $h$ is:

$$
\frac{\partial h}{\partial\left[k^{\alpha}\left(\frac{A}{B}\right)^{1-\alpha}\right]}=\frac{1-k^{\alpha}\left(\frac{A}{B}\right)^{1-\alpha}}{\left[k^{\alpha}\left(\frac{A}{B}\right)^{1-\alpha}+1\right]^{3}}=0
$$

or

A.1.

$$
k^{\alpha}\left(\frac{A}{B}\right)^{1-\alpha}=1
$$

or

$$
k^{\frac{\alpha}{1-\alpha}}\left[\frac{\left(d_{1} \delta_{1 x}\right)^{\frac{1}{1-\alpha}}+\left(d_{2} \delta_{2 x}\right)^{\frac{1}{1-\alpha}}}{\left(d_{1} \delta_{1 y}\right)^{\frac{1}{1-\alpha}}+\left(d_{2} \delta_{2 y}\right)^{\frac{1}{1-\alpha}}}\right]=1
$$

and the SOC when $k^{\alpha}\left(\frac{A}{B}\right)^{1-\alpha}=1$ is satisfied:

$$
\frac{\partial^{2} h}{\partial\left[k^{\alpha}\left(\frac{A}{B}\right)^{1-\alpha}\right]^{2}}=-\frac{1}{\left[k^{\alpha}\left(\frac{A}{B}\right)^{1-\alpha}+1\right]^{3}}<0
$$


Notice that the expressions $\sum_{i=1}^{2} x_{i}, \sum_{i=1}^{2} y_{i}$ and $\sum_{i=1}^{2} x_{i}+\sum_{i=1}^{2} y_{i}$ are differentiated with respect to $k^{\alpha}\left(\frac{A}{B}\right)^{1-\alpha}$. This means that when A.1 is satisfied, a change in $\frac{A}{B}$ reduces the contestants' efforts (separately and jointly). However, if A.1 is satisfied, a change in $k$ reduces efforts, but it also involves a change in $n_{x}$ and $n_{y}$ that also affect efforts. Hence, a change in $k$ reduces $\sum_{i=1}^{2} x_{i}$, provided that $n_{x}$ is unaltered ( $n_{y}$ is changed). Similarly, $\sum_{i=1}^{2} y_{i}$ is reduced, provided that $n_{y}$ is unaltered $\left(n_{x}\right.$ is changed $)$ and $\sum_{i=1}^{2} x_{i}+\sum_{i=1}^{2} y_{i}$ will reduce when $\left(n_{x}+n_{y}\right)$ is unchanged.

Substituting A.1 in (5), (6) and (7) gives $\sum_{i=1}^{N} x_{i}=0.25 \alpha n_{x}, \sum_{i=1}^{N} y_{i}=0.25 \alpha n_{y}$, $\sum_{i=1}^{2} x_{i}+\sum_{i=1}^{2} y_{i}=0.25 \alpha\left(n_{x}+n_{y}\right) \quad$ and $\quad p_{x}=p_{y}=0.5 . \quad$ Substituting $\quad \delta_{1 x}=\delta_{2 x} \quad$ and $\delta_{1 y}=\delta_{2 y}$ in equation A.1 and combining $\delta_{1 x}+\delta_{1 y}=\delta_{2 x}+\delta_{2 y}=1$ implies that $\delta_{1 x}=\delta_{2 x}=\frac{1}{1+k^{\alpha}}$ and $\delta_{1 y}=\delta_{2 y}=\frac{k^{\alpha}}{1+k^{\alpha}}$. Therefore, in this case the efforts directed by the interest groups to the parties are maximal, $\sum_{i=1}^{2} x_{i}+\sum_{i=1}^{2} y_{i}=0.25 \alpha\left(n_{x}+n_{y}\right)$ and $p_{x}=p_{y}=0.5$.

Proof of Theorem 5 part (b): By the proof of Theorem 5 part (a), Substituting $\delta_{1 x}=1$ and $\delta_{2 x}=0$ in equation A.1 and combining $\delta_{1 x}+\delta_{1 y}=\delta_{2 x}+\delta_{2 y}=1$ gives $d_{1}=\frac{1}{1+k^{\alpha}}$. Therefore, in this case the efforts of the interest groups are maximal, $\sum_{i=1}^{2} x_{i}+\sum_{i=1}^{2} y_{i}=0.25 \alpha\left(n_{x}+n_{y}\right)$ and $p_{x}=p_{y}=0.5$.

Proof of the Remark: When both interest groups are not effective, from the proof of Theorem 1 get that the following equality is satisfied: 


$$
f(z)=\frac{1+z^{\beta}}{(1+z)^{\beta}}=\frac{1+w^{\beta}}{(1+w)^{\beta}}=f(w)
$$

since $f(a)=f\left(\frac{1}{a}\right), f(z)=f(w)$ if and only if $w=z$ or $w=\frac{1}{z}$ :

1. When $w=z$ we get that $\delta_{1 x}=\delta_{2 x}$ (or $\delta_{2 y}=\delta_{1 y}$ ). Since the efforts are maximal, $p_{x}=p_{y}=0.5$. Since no interest group is effective, the probability of interest group $x$ 's with no contest is $d_{1} \delta_{1 x}+d_{2} \delta_{2 x}=0.5$. Substituting in the last equality $\delta_{1 x}=\delta_{2 x}$ we get that $\delta_{1 x}=\delta_{2 x}=0.5$ and therefore $\delta_{1 x}=\delta_{2 x}=\delta_{1 y}=\delta_{2 y}=0.5$. By Theorem 5 part (a), for these values the efforts directed by the interest groups to the parties are maximal.

2. When $w=\frac{1}{z}$ we get $\frac{d_{2} \delta_{2 y}}{d_{1} \delta_{1 y}}=\frac{d_{1} \delta_{1 x}}{d_{2} \delta_{2 x}}$ or $\frac{d_{2}}{d_{1}}=\left(\frac{\delta_{1 x} \delta_{1 y}}{\delta_{2 x} \delta_{2 y}}\right)^{0.5}$. Since the efforts are maxima, $p_{x}=p_{y}=0.5$. Since no interest group is effective, the probabilities of both interest groups with no contest are identical:

$$
\begin{gathered}
d_{1} \delta_{1 x}+d_{2} \delta_{2 x}=d_{1} \delta_{1 y}+d_{2} \delta_{2 y}(=0.5) \\
\frac{d_{2}}{d_{1}}=\frac{\delta_{1 x}-\delta_{1 y}}{\delta_{2 y}-\delta_{2 x}}
\end{gathered}
$$

Substituting in the last equality the additional condition for no effectiveness of the interest groups, $\frac{d_{2}}{d_{1}}=\left(\frac{\delta_{1 x} \delta_{1 y}}{\delta_{2 x} \delta_{2 y}}\right)^{0.5}$, we get the following equivalent conditions: $\quad\left(\frac{\delta_{1 x} \delta_{1 y}}{\delta_{2 x} \delta_{2 y}}\right)^{0.5}=\frac{\delta_{1 x}-\delta_{1 y}}{\delta_{2 y}-\delta_{2 x}} \quad$ or $\quad \frac{\delta_{1 x} \delta_{1 y}}{\delta_{2 x} \delta_{2 y}}=\left(\frac{\delta_{1 x}-\delta_{1 y}}{\delta_{2 y}-\delta_{2 x}}\right)^{2} \quad$ or $\frac{\delta_{1 x} \delta_{1 y}}{\delta_{2 x} \delta_{2 y}}=\frac{\delta_{1 x}^{2}-2 \delta_{1 x} \delta_{1 y}+\delta_{1 y}^{2}}{\delta_{2 y}^{2}-2 \delta_{2 y} \delta_{2 x}+\delta_{2 x}^{2}}$. After some simplifications we get:

$$
\left(\delta_{2 y} \delta_{1 x}-\delta_{1 y} \delta_{2 x}\right)\left(\delta_{2 y} \delta_{1 y}-\delta_{1 x} \delta_{2 x}\right)=0
$$

Substituting $\delta_{2 y}=1-\delta_{2 x}$ and $\delta_{1 y}=1-\delta_{1 x}$ into last equation we get $\left(\delta_{1 x}-\delta_{2 x}\right)\left(1-\delta_{1 x}-\delta_{2 x}\right)=0$, or:

$$
\left(\delta_{1 x}-\delta_{2 x}\right)\left(\delta_{1 y}-\delta_{2 x}\right)=0
$$


This equality is satisfied if $\delta_{1 x}=\delta_{2 x}\left(\delta_{1 y}=\delta_{2 y}\right)$ or $\delta_{1 y}=\delta_{2 x}\left(\delta_{1 x}=\delta_{2 y}\right)$. Let's check both cases:

2.1. $\delta_{1 x}=\delta_{2 x}$ - since no interest group is effective, $d_{1} \delta_{1 x}+d_{2} \delta_{2 x}=0.5$. Substituting in the last equality $\delta_{1 x}=\delta_{2 x}$ we get $\delta_{1 x}=\delta_{2 x}=0.5$ and therefore $\delta_{1 x}=\delta_{2 x}=\delta_{1 y}=\delta_{2 y}=0.5$. By Theorem 5 part (a), for these values the efforts of the interest groups are maximal.

2.2. $\delta_{1 y}=\delta_{2 x}\left(\delta_{1 x}=\delta_{2 y}\right)$ - Substituting in the equality $\frac{d_{2}}{d_{1}}=\left(\frac{\delta_{1 x} \delta_{1 y}}{\delta_{2 x} \delta_{2 y}}\right)^{0.5}$ we get $d_{1}=d_{2}=0.5$. For these values the efforts directed by the interest groups to the parties are maximal.

\section{Proof of Theorem 6.1:}

Since:

$$
\begin{aligned}
& \frac{\partial\left(\sum_{i=1}^{2} x_{i}\right)}{\partial \delta_{j x}}=\frac{\alpha n_{x} k^{\alpha} d_{j}^{\frac{1}{1-\alpha}}\left[\delta_{j x}^{\frac{\alpha}{1-\alpha}}+\left(1-\delta_{j x}\right) \frac{\alpha}{1-\alpha} \frac{A}{B}\right]\left[1-k^{\alpha}\left(\frac{A}{B}\right)^{1-\alpha}\right]}{\left[k^{\alpha}\left(\frac{A}{B}\right)^{1-\alpha}+1\right]^{3}\left(\frac{A}{B}\right)^{\alpha} B} \\
& \frac{\partial\left(\sum_{i=1}^{2} y_{i}\right)}{\partial \delta_{j x}}=\frac{\alpha n_{y} k^{\alpha} d_{j}^{\frac{1}{1-\alpha}}\left[\delta_{j x}^{\frac{\alpha}{1-\alpha}}+\left(1-\delta_{j x}\right)^{\frac{\alpha}{1-\alpha}} \frac{A}{B}\right]\left[1-k^{\alpha}\left(\frac{A}{B}\right)^{1-\alpha}\right]}{\left[k^{\alpha}\left(\frac{A}{B}\right)^{1-\alpha}+1\right]^{3}\left(\frac{A}{B}\right)^{\alpha} B} \\
& \frac{\partial\left(\sum_{i=1}^{2} x_{i}+\sum_{i=1}^{2} y_{i}\right)}{\partial \delta_{j x}}=\frac{\alpha k^{\alpha}\left(n_{x}+n_{y}\right) d_{j}^{\frac{1}{1-\alpha}}\left[\delta_{j x}^{\frac{\alpha}{1-\alpha}}+\left(1-\delta_{j x}\right) \frac{\alpha}{1-\alpha} \frac{A}{B}\right]\left[1-k^{\alpha}\left(\frac{A}{B}\right)^{1-\alpha}\right]}{\left[k^{\alpha}\left(\frac{A}{B}\right)^{1-\alpha}+1\right]^{3}\left(\frac{A}{B}\right)^{\alpha} B} \\
& \text { Therefore, } \frac{\partial\left(\sum_{i=1}^{2} x_{i}\right)}{\partial \delta_{j x}}>0, \frac{\partial\left(\sum_{i=1}^{2} y_{i}\right)}{\partial \delta_{j x}}>0 \text { and } \frac{\partial\left(\sum_{i=1}^{2} x_{i}+\sum_{i=1}^{2} y_{i}\right)}{\partial \delta_{j x}}>0 \text {, if and only if } \\
& k^{\alpha}\left(\frac{A}{B}\right)^{1-\alpha}<1 .
\end{aligned}
$$




\section{Proof of Theorem 6.2:}

Since:

$$
\begin{gathered}
\frac{\partial\left(\sum_{i=1}^{2} x_{i}\right)}{\partial d_{1}}=\frac{\alpha n_{x} k^{\alpha}\left(d_{1} d_{2}\right)^{\frac{\alpha}{1-\alpha}}\left[1-k^{\alpha}\left(\frac{A}{B}\right)^{1-\alpha}\right]\left[\left(\delta_{1 x} \delta_{2 y}\right)^{\frac{1}{1-\alpha}}-\left(\delta_{1 y} \delta_{2 x}\right)^{\frac{1}{1-\alpha}}\right]}{\left[k^{\alpha}\left(\frac{A}{B}\right)^{1-\alpha}+1\right]^{3}\left(\frac{A}{B}\right)^{\alpha} B^{2}} \\
\frac{\partial\left(\sum_{i=1}^{2} y_{i}\right)}{\partial d_{1}}=\frac{\alpha n_{y} k^{\alpha}\left(d_{1} d_{2}\right)^{\frac{\alpha}{1-\alpha}}\left[1-k^{\alpha}\left(\frac{A}{B}\right)^{1-\alpha}\right]\left[\left(\delta_{1 x} \delta_{2 y}\right)^{\frac{1}{1-\alpha}}-\left(\delta_{1 y} \delta_{2 x}\right)^{\frac{1}{1-\alpha}}\right]}{\left[k^{\alpha}\left(\frac{A}{B}\right)^{1-\alpha}+1\right]^{3}\left(\frac{A}{B}\right)^{\alpha} B^{2}} \\
\frac{\partial\left(\sum_{i=1}^{2} x_{i}+\sum_{i=1}^{2} y_{i}\right)}{\partial d_{1}}=\frac{\alpha k^{\alpha}\left(n_{x}+n_{y}\right)\left(d_{1} d_{2}\right)^{\frac{\alpha}{1-\alpha}}\left[1-k^{\alpha}\left(\frac{A}{B}\right)^{1-\alpha}\right]\left[\left(\delta_{1 x} \delta_{2 y}\right)^{\frac{1}{1-\alpha}}-\left(\delta_{1 y} \delta_{2 x}\right)^{\frac{1}{1-\alpha}}\right]}{\partial\left(k^{\alpha}\left(\frac{A}{B}\right)^{1-\alpha}+1\right]^{3}\left(\frac{A}{B}\right)^{\alpha} B^{2}} \\
\frac{\partial\left(\sum_{i=1}^{2} x_{i}\right)}{\left.\partial d_{1} y_{i}\right)}>0, \frac{\partial d_{1}}{\left[\sum_{i=1}^{2} x_{i}+\sum_{i=1}^{2} y_{i}\right)^{2}}>0, \text { if and only if: } \\
\frac{\partial d_{1}}{1-k^{\alpha}\left(\frac{A}{B}\right)^{1-\alpha}}\left[\left(\delta_{1 x} \delta_{2 y}\right)^{\frac{1}{1-\alpha}}-\left(\delta_{1 y} \delta_{2 x}\right)^{\frac{1}{1-\alpha}}\right]>0
\end{gathered}
$$

Moreover:

$$
\operatorname{sign}\left[\left(\delta_{1 x} \delta_{2 y}\right)^{\frac{1}{1-\alpha}}-\left(\delta_{1 y} \delta_{2 x}\right)^{\frac{1}{1-\alpha}}\right]=\operatorname{sign}\left(\delta_{2 y}-\delta_{1 y}\right)
$$

therefore $\left[1-k^{\alpha}\left(\frac{A}{B}\right)^{1-\alpha}\right]\left[\left(\delta_{1 x} \delta_{2 y}\right)^{\frac{1}{1-\alpha}}-\left(\delta_{1 y} \delta_{2 x}\right)^{\frac{1}{1-\alpha}}\right]>0$ if and only if:

$$
\left[1-k^{\alpha}\left(\frac{A}{B}\right)^{1-\alpha}\right]\left(\delta_{2 y}-\delta_{1 y}\right)>0
$$

\section{Proof of Theorem 6.3:}

(a) Since, 


$$
\frac{\partial x_{j}}{\partial n_{x}}=\frac{\alpha k^{\alpha}\left(d_{j} \delta_{j x}\right)^{\frac{1}{1-\alpha}}\left(\frac{A}{B}\right)^{1-\alpha}\left[(1-\alpha) k^{\alpha}\left(\frac{A}{B}\right)^{1-\alpha}+1+\alpha\right]}{\left[k^{\alpha}\left(\frac{A}{B}\right)^{1-\alpha}+1\right]^{3} A}>0, \frac{\partial\left(\sum_{i=1}^{2} x_{i}\right)}{\partial n_{x}}>0 .
$$

Also:

$$
\frac{\partial x_{j}}{\partial n_{y}}=\frac{\alpha^{2}\left(d_{j} \delta_{j x}\right)^{\frac{1}{1-\alpha}} n_{x}^{1+\alpha} n_{y}{ }^{2 \alpha-1}\left[k^{\alpha}\left(\frac{A}{B}\right)^{1-\alpha}-1\right]}{\left[n_{x}^{\alpha}\left(\frac{A}{B}\right)^{1-\alpha}+n_{y}^{\alpha}\right]^{3}\left(\frac{A}{B}\right)^{\alpha} B}
$$

and therefore $\frac{\partial x_{j}}{\partial n_{y}}>0$ and $\frac{\partial\left(\sum_{i=1}^{2} x_{i}\right)}{\partial n_{y}}>0$, if and only if $k^{\alpha}\left(\frac{A}{B}\right)^{1-\alpha}>1$.

Furthermore,

$$
\frac{\partial y_{j}}{\partial n_{x}}=\frac{\alpha^{2}\left(d_{j} \delta_{j y}\right)^{\frac{1}{1-\alpha}}\left(\frac{A}{B}\right)^{1-\alpha} n_{x}^{\alpha-1} n_{y}{ }^{1+2 \alpha}\left[1-k^{\alpha}\left(\frac{A}{B}\right)^{1-\alpha}\right]}{\left[n_{x}^{\alpha}\left(\frac{A}{B}\right)^{1-\alpha}+n_{y}^{\alpha}\right]^{3} B}
$$

Hence, $\frac{\partial y_{j}}{\partial n_{x}}>0$ and $\frac{\partial\left(\sum_{i=1}^{2} y_{i}\right)}{\partial n_{x}}>0$, if and only if $k^{\alpha}\left(\frac{A}{B}\right)^{1-\alpha}<1$. Moreover, since it is always true that $\frac{\partial\left(\sum_{i=1}^{2} x_{i}\right)}{\partial n_{x}}>0$, the last condition, $k^{\alpha}\left(\frac{A}{B}\right)^{1-\alpha}<1$, is a sufficient one for $\frac{\partial\left(\sum_{i=1}^{2} x_{i}+\sum_{i=1}^{2} y_{i}\right)}{\partial n_{x}}>0$. By symmetry $\frac{\partial\left(\sum_{i=1}^{2} x_{i}+\sum_{i=1}^{2} y_{i}\right)}{\partial n_{y}}>0$, if $k^{\alpha}\left(\frac{A}{B}\right)^{1-\alpha}>1$.

change in $k$ reduces $\sum_{i=1}^{2} x_{i}+\sum_{i=1}^{2} y_{i}$ when $\left(n_{x}+n_{y}\right)$ is unchanged. 
(c) According the proof of Theorem 5 part (a), if A.1 is satisfied $\left(k^{\alpha}\left(\frac{A}{B}\right)^{1-\alpha}=1\right)$, the maximal contestants' total effort is $\sum_{i=1}^{2} x_{i}+\sum_{i=1}^{2} y_{i}=0.25 \alpha\left(n_{x}+n_{y}\right)$. Therefore, if the interest groups have equal incentives, then increasing (decreasing) both $n_{x}$ and $n_{y}$ such that $k$ is unchanged, increases (reduces) the contestants' efforts. 